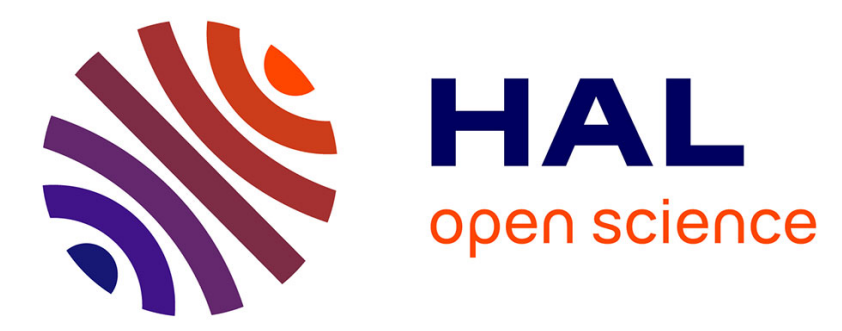

\title{
On the Origin of the Anisotropic Damage of X100 Line Pipe Steel: Part I-In Situ Synchrotron Tomography Experiments
}

Yazid Madi, J.-M. Garcia, Henry Proudhon, Y. Shinohara, L. Helfen, Jacques Besson, Thilo F. Morgeneyer

\section{To cite this version:}

Yazid Madi, J.-M. Garcia, Henry Proudhon, Y. Shinohara, L. Helfen, et al.. On the Origin of the Anisotropic Damage of X100 Line Pipe Steel: Part I-In Situ Synchrotron Tomography Experiments. Integrating Materials and Manufacturing Innovation, 2019, 8 (4), pp.570-596. 10.1007/s40192-01900165-0 . hal-02437184

\author{
HAL Id: hal-02437184 \\ https://hal.science/hal-02437184
}

Submitted on 27 Nov 2020

HAL is a multi-disciplinary open access archive for the deposit and dissemination of scientific research documents, whether they are published or not. The documents may come from teaching and research institutions in France or abroad, or from public or private research centers.
L'archive ouverte pluridisciplinaire HAL, est destinée au dépôt et à la diffusion de documents scientifiques de niveau recherche, publiés ou non, émanant des établissements d'enseignement et de recherche français ou étrangers, des laboratoires publics ou privés. 


\title{
On the origin of the anisotropic damage of X100 line pipe steel \\ Part I: In-situ synchrotron tomography experiments
}

\author{
Madi, Y. ${ }^{\mathrm{a}, \mathrm{b}}$, Garcia, J-M. ${ }^{\mathrm{a}}$, Proudhon, H. ${ }^{\mathrm{a}}$, Shinohara, Y. ${ }^{\mathrm{d}}$, Helfen, L. ${ }^{\mathrm{c}}$, \\ Besson, J. ${ }^{\mathrm{a}}$, Morgeneyer, T.F. ${ }^{\mathrm{a}}$ \\ ${ }^{a}$ MINES ParisTech, PSL Research University, Centre des Matériaux, CNRS UMR 7633, \\ BP 8791003 Evry, France \\ ${ }^{b}$ EPF - École d'ingénieur-e-s, 3 bis rue Lakanal, Sceaux, France \\ ${ }^{c}$ ESRF, 71 Avenue des Martyrs, 38000 Grenoble, France \\ ${ }^{d}$ Nippon Steel Corporation, Tokyo, Japan
}

\begin{abstract}
In this study, anisotropic ductility and associated damage mechanisms of a grade X100 line pipe steel previously studied at the macroscopic scale, were investigated using in-situ synchrotron-radiation computed tomography (SRCT) of notched round bars. Line pipe materials have anisotropic mechanical properties, such as tensile strength, ductility and toughness. Specimens were tested for loading along both rolling $(\mathrm{L})$ and transverse $(\mathrm{T})$ directions. The in-situ data collected allowed quantifying both specimen deformation (evolution of the cross section) and microscopic damage parameters such as porosity, void shape and void orientation.

Nucleation at small particles $\left(\mathrm{CaS} / \mathrm{TiO}_{2}\right)$ aligned along the $\mathrm{L}$ direction was observed during plastic deformation. It was shown that only very few anisotropic particle clusters are present in the material. However, these clusters led to substantial early void growth for loading normal to the loading direction, thereby explaining the toughness anisotropy in this material. Significant void growth was observed at the beginning of load decrease for a relatively limited diameter reduction (about 10\%). Coalescence of voids within clusters along L-direction (Necklace) clearly explained anisotropic rupture.
\end{abstract}

Keywords: Anisotropy, rupture, plasticity, X100, line pipe steel, synchrotron tomography, in-situ mechanical testing

Preprint submitted to Integrating Materials and Manufacturing InnovationNovember 5, 2019 


\section{Introduction}

Anisotropic plastic and rupture behavior is observed on many engineering materials, particularly on rolled sheet metal which are the basic elements of certain structural components: line pipe steels used for energy transportation, structural elements of aircraft made of aluminum alloy (Morgeneyer et al. (2009); Chen et al. (2011) ) or magnesium alloy which is a material of the future and potential candidate to replace various structural elements (Kondori et al. (2018); Herrington et al. (2019)). Anisotropy here refers both to the deformation process related to anisotropic plasticity and also to the anisotropic rupture process.

a)

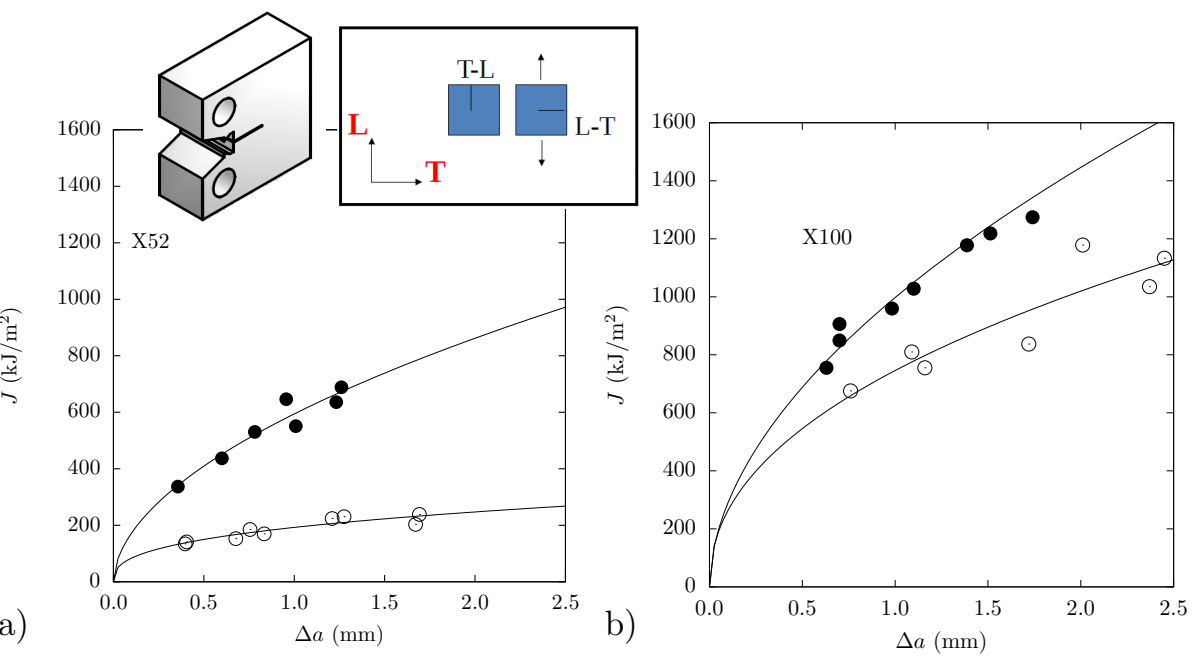

Figure 1: Evolution of toughness on line pipe steels: $J-\Delta a$ curves for the $\mathrm{L}-\mathrm{T}$ and $\mathrm{T}-\mathrm{L}$ configurations (CT specimens, $B=12.5 \mathrm{~mm}$ ) on a) grade X52 (Benzerga $(2000)$ ) and b) grade X100 (Shinohara et al. (2016)).

In this study, anisotropic ductility of a modern API X100 high grade line pipe steel plate is investigated using in-situ synchrotron-radiation computed tomography (SRCT). This material was studied in previous work at a macroscopic scale (see Shinohara et al. (2016)). It was shown that the plastic behavior is anisotropic and that it can be adequately described using the model proposed by Bron and Besson (2004). Rupture properties are also anisotropic in terms of both ductility (tensile bars) and crack growth resistance (CT and SENB tests). However, the anisotropic fracture behavior could not be reproduced numerically as the model only account for anisotropy plastic. The origins of fracture anisotropy are the topic of the present paper.

Fracture properties have been improved considerably over the last decades, as shown by the comparison of the toughness of a "vintage" line pipe steel, X52, and a "modern" one, X100, (Figure 1). This has contributed to a significant increase of internal pressure to satisfy the increase of natural gas demand. Understanding of rupture anisotropy of "vintage" line pipe steel have been well 
described by Benzerga et al. (2004) using 2D SEM observations. The strong anisotropy has been related to voids spacing of elongated inclusions (Benzerga (2000) ) and aligned particles within clusters (Benzerga et al. (2004); Pardoen (1998)) that lead to "necklace" formation. For "modern" X100 line pipe steel, 2D examinations of fracture surfaces or polished cross sections could not clearly show spacing anisotropy (see Shinohara et al. (2016)). This could be due to the very low inclusion content (volume fraction around $2 \times 10^{-4}$ ) which renders measurements difficult. The origin of the damage anisotropy analysis using $2 \mathrm{D}$ observations may be very cumbersome, 3D observations during loading should be more adapted.

In situ tomography is a suitable tool to assess damage micro-mechanisms in qualitative and quantitative manner at the micrometer scale. Damage kinetics in aluminum alloys have been studied in Maire et al. (2011) also in dual phase steels Landron et al. (2011). Intergranular damage in 316L has been studied in-situ in Pommier et al. (2016). The anisotropic effect of particle cluster distribution on fracture has been studied in Hannard et al. (2018). Damage prediction can even be performed numerically via meshing real microstructures and driving simulations with measured 3D boundary conditions Buljac et al. (2017).

The purpose of the present work is to explain the origin of anisotropic rupture of a modern line pipe steel based on microscopic tomographic in-situ observations. The study presented herein constitutes a first part of a twofold investigation. This first paper is focused on the in-situ synchrotron tomography experiments. A second paper is dedicated to a comparison with finite element simulation based on micro-mechanical modeling to predict anisotropic damage. A deeper quantitative analysis is proposed to track local damage and compare with modeling. In the present study, small axisymmetric notched tensile samples (1.2 mm minimum diameter) were in-situ tested using SRCT at the European Synchrotron Radiation Facility (ESRF) (Sect. 2). Specimens were tested along two different directions ; The observations allowed describing all steps leading to failure: plastic hardening, necking, damage growth, crack initiation and propagation (Sect. 3). The in-situ data collected allowed quantifying both macroscopic deformation (evolution of the cross section, (Sect. 3.1) and microscopic damage parameters such as: porosity, void shape and void orientation, (Sect. 3.2).

\section{Material and experimental methods}

\subsection{Material}

The material of this study is an API X100 high grade line pipe steel extracted from a $16 \mathrm{~mm}$ wall thickness heavy plate. Because of the thermomechanical controlled rolling and accelerated cooling (TMCP) process, this material exhibits a pronounced anisotropy, (see Tanguy et al. (2008); Shinohara et al. (2016). Keeping track of its main axes is of great importance for the study. The principal axis are $\mathrm{L}$, the rolling direction; $\mathrm{T}$, the transverse direction and $\mathrm{S}$, the 
short transverse. Compared to a pipe, which is usually produced by UOE forming 1 , the plate can be considered as being in an unprestrained state. Material composition is detailed in Table 1. The microstructure consists of a dual phase structure of fine polygonal ferrite and bainite. The most significant inclusions are calcium sulfide $(\mathrm{CaS})$ or titanium oxide $\left(\mathrm{TiO}_{2}\right)$, Shinohara (2014).

\begin{tabular}{ccccccc}
\hline $\mathbf{C}$ & $\mathbf{S i}$ & $\mathbf{M n}$ & $\mathbf{P}$ & $\mathbf{S}$ & $\mathbf{T i}$ & $\mathbf{N}$ \\
\hline 0.051 & 0.20 & 1.95 & 0.007 & 0.0015 & 0.012 & 0.0004 \\
\hline
\end{tabular}

Table 1: Nominal chemical composition.

\subsection{X-ray tomography}

X-ray microtomography was applied to obtain 3D images at the European Synchrotron Radiation Facility (ESRF, beamline ID15a). Contrast is obtained by coherent X-rays according to the Beer-Lambert's Absorption law using a white beam (peak energy set at $60 \mathrm{keV}$ ). Typical volume of interest was around $3.3 \mathrm{~mm}^{3}\left(1495 \times 1495 \times 1600\right.$ voxels) with a voxel size of $1.095 \mathrm{\mu m}^{3}$ (true spatial resolution around $2 \mu \mathrm{m}$, Di Michiel et al. (2005)). With these parameters a total time scan was 2.5 mins (time exposure of $1.8 \mathrm{~ms}$ ). It was subsequently reconstructed from 4000 projections. Some ring-shaped artifacts could also be observed. They are inherent to the tomography technique and were removed thereafter from the complete 3D reconstructions. Reconstructed volumes were not filtered as the quality of images was high enough. Segmentation of the volumes were performed using a simple threshold (threshold value of 120 for 8-bit grayscale images) to distinguish the cavities from the steel phase. The 3D images were segmented using three gray levels: 0 for the cavities, 100 for the air surrounding the specimen and 255 fo the steel phase. The volumes were aligned so that specimen axis could be parallel to the image borders. All 3D images were visualized using a python package (https://github.com/heprom/ pymicro) and the VTK library. For that purpose, the air around the specimen was also segmented. All 3D volumes have been made available as a dataset in Madi et al. (2019) using hdf5 and xdmf standarded exchange formats.

\subsection{In situ testing procedure}

A dedicated in-situ tensile machine was mounted on the rotation stage of the ID15a tomography and station displacement controlled with a fixed imposed velocity of $5 \times 10^{-3} \mathrm{~mm} / \mathrm{s}$ and a load cell capacity of $5 \mathrm{kN}$ (see Buffière et al. (2010) for more details on the machine). Two small axisymmetric notched tensile bars were machined having their main axis parallel to typical directions of the plate (see Fig. 2). The first was parallel to the rolling direction (Lspecimen) and the second to the long transverse direction (T-specimen). This

\footnotetext{
${ }^{1}$ The stock plate is subjected to cold working by a C-press, a U-press, an O-press, a seam welding, and an expander in that order, (see Tsuru et al. (2013)).
} 
a)

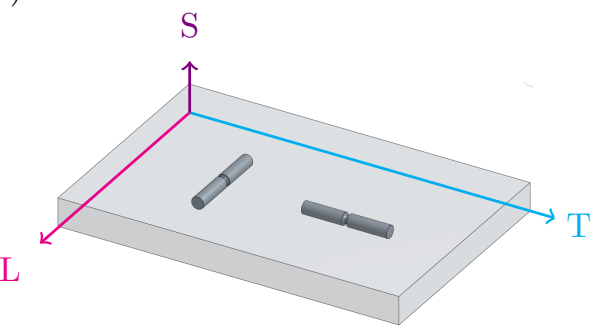

c)

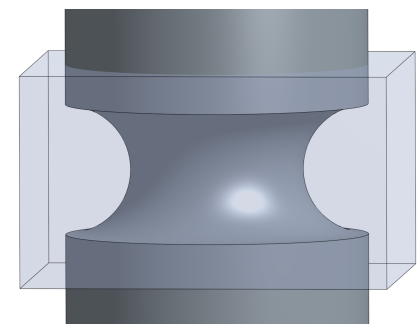

b)

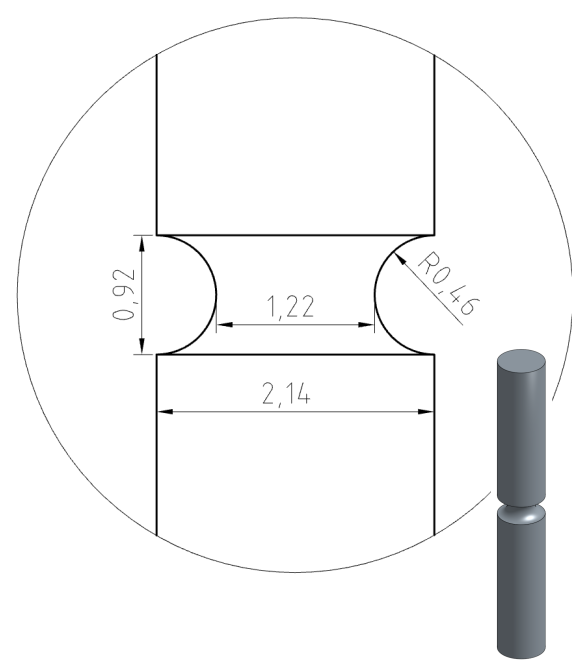

Figure 2: a) Specimens directions; b) Specimen geometry and c) Scanned zone.

microscale geometry corresponds to a macroscale geometry $\mathrm{NT}_{4}$ used previously to characterize both plastic behavior and damage evolution (see Shinohara et al. (2016), a maximum triaxiality of around 1 expected in the center). Tests were performed along both $\mathrm{L}$ and $\mathrm{T}$ directions and were interrupted at various stages of deformation to perform scans (Fig. 3, 17 steps for L loading and 11 steps for T loading). The crosshead displacement of the tensile machine was stopped during the scan acquisition. Once the load was stabilized after relaxation, scans were performed. The first step was done with a negligible load so that the specimen could be aligned. The in-situ tests allowed investigation of all steps leading to failure: plastic hardening, necking, damage growth, crack initiation and propagation.

\subsection{Macroscopic measurements}

The outer shape of the sample, as seen in the tomography image, was used to determine the local values of radial contractions along the main directions: $\mathrm{T}$ and $\mathrm{S}$ directions for $\mathrm{L}$ loading specimen and $\mathrm{L}$ and $\mathrm{S}$ directions for $\mathrm{T}$ loading direction. As the deformation was anisotropic, the measurement of the radial contractions have been made using the following procedure: i) the initial circular cross-section was assumed to deform into an elliptical geometry, ii) an ellipse fitting the minimal cross-section outline was calculated for each step, iii) principal axis lengths were extracted to get the lateral radial contractions. An ellipse was drawn in the $2 \mathrm{D}$ slice centered to the center of mass for each step to check the procedure as shown in the appendix (Figs. A.26 A.27). An 

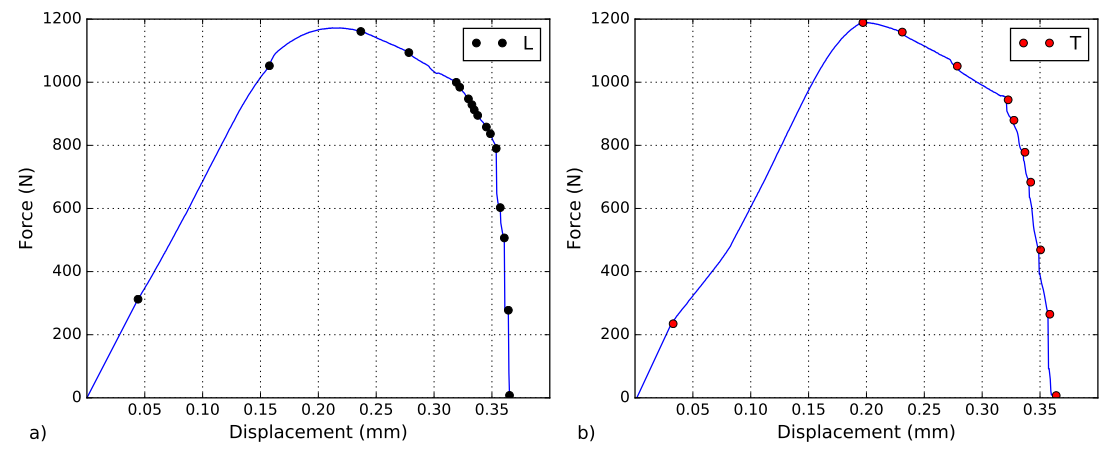

Figure 3: Load Displacement curves of the in-situ NT tests: a) L-specimen, b) T-specimen. $(\operatorname{dots}(\bullet, \bullet)$ corresponds to the tomography scans. The stopped machine stages have been removed from the tensile curves.

average value of the true strain in the minimal cross-section can be related to the direct measurement of area of the minimal surface $A: \varepsilon_{\text {loc }}=\ln \left(\frac{A_{0}}{A}\right), A_{0}$ represents the initial value of the net section area. Anisotropic deformation was evaluated using the Lankford-like coefficient $\mathcal{L}$ defined as follows: $\mathcal{L}_{\|}=\varepsilon_{\perp}^{p} / \varepsilon_{\mathrm{S}}^{p}$ considering plastic strains where $\|$ corresponds to the loading direction and $\perp$ to the direction perpendicular to both the loading and $\mathrm{S}$ directions. The Lankford coefficient was proposed for uniaial stress states. The stress state is multiaxial here. $\varepsilon^{p}$ corresponds to the true plastic strain (the true strain for each direction is evaluated as $\varepsilon=\ln \left(\Phi / \Phi_{0}\right), \Phi$ is the actual diameter).

\subsection{Microscopic measurements}

After segmentation, cavities were treated as particles and labeled using Python (scipy.ndimage), Jones et al. (01). Thanks to conclusions by Landron et al. (2012), the particles having a an equivalent diameter smaller than $1.7 \mu \mathrm{m}$ were not included in the analysis. Many morphological features have been calculated in order to characterize the evolution of the complex 3D shapes, Walton (1948); Merkus (2009). Basics measures (such as volume $V$, surface area $A$, equivalent spherical diameter $D_{e q}=\sqrt[3]{\frac{6 V}{\pi}}$ ), shape indexes (such as Feret's shape factors) and mass distribution parameters have been computed. From the void segmentation, moments of inertia $I_{i j}$ have been computed in the local frame of the specimen. The eigenvectors and the eigenvalues of the $I_{i j}$ tensor respectively give the principal directions and the principal moments of inertia $I_{1}, I_{2}, I_{3}$. They were normalized by their summation to be independent of the volume and denoted $\lambda_{i}=I_{i} /\left(I_{1}+I_{2}+I_{3}\right), i=1,2,3$ (their sum is equal to 1 ). The shape of the particle is then equivalent to an ellipsoid having the same moment of inertia as the real shape, (see Denis et al. (2008); Borbély et al. (2004)). From the kinematic point of view, the local orientation of a particle is defined as that of the axis around which the particle rotates with the minimum inertia. The calculation of the local orientation is then reduced to the search for 
the main axis of inertia of the particle which is determined by the eigenvector $u$ associated with the minimum eigenvalue of the inertia matrix. The orientation of the particles was characterized by the angle $\gamma=\arccos \left(\frac{u_{i}}{\|u\|}\right)$ between the principal axis of the equivalent ellipsoid and the material direction $\mathrm{L}(i=3$ for $\mathrm{L}$ loading sample and $i=1$ for $\mathrm{T}$ loading specimen). $\gamma=0$ therefore corresponds to a cavity oriented along the $\mathrm{L}$ direction.

All the scripts used to analyse both macroscopic and microscopic tests have been made available as a dataset in Madi et al. (2019).

\section{Results}

\subsection{Anisotropic plastic behavior and ductility}

Fig. 4 shows the experimental force - diameter reduction curves for notched bars tested in $\mathrm{T}$ and $\mathrm{L}$ directions. Ellipses, drawn for the different loading steps (here two cases for each loading direction), fit with an excellent agreement with the minimal cross-section areas confirming the elliptical deformation hypothesis of the cross-section. Deformation along the $\mathrm{S}$ direction is larger than in the $\perp$ direction. Anisotropy in terms of maximum stress $F / S_{0} \|_{\max }$ exists but remains limited $(<2 \%)$; on the other hand deformation anisotropy is marked as Lankford-like coefficients $\mathcal{L}$ strongly differ from 1 . Curves present a sharp load drop (corresponding of load steps number (12) and (6) for L loading direction and $\mathrm{T}$ loading direction respectively in fig. 4) which corresponds to the initiation of a macroscopic crack at the center of the specimens. The corresponding ("critical") diameter reduction is referred to as: $\Delta \Phi_{\mathrm{S}} / \Phi_{0} \|_{c}$. This load is $10 \%$ higher in the case of $\mathrm{T}$ loading due to plastic and ductile anisotropy. The sharp load drop occurs for lower critical diameter reductions for $\mathrm{T}$ loading direction. Table 2 summarizes the main macroscopic properties extracted from the in-situ testing. The area reduction at failure $Z$ also indicate that ductility is slightly lower for T loading. All the critical values of stress and ductility are consistent with those obtained on the macroscale $\mathrm{NT}_{4}$ specimens testing in the previous study, Shinohara et al. (2016).

\begin{tabular}{lcccccc} 
Orientation & $\begin{array}{c}F / S_{0} \|_{\max } \\
(\mathrm{MPa})\end{array}$ & $\begin{array}{c}F / S_{0} \|_{c} \\
(\mathrm{MPa})\end{array}$ & $\begin{array}{c}\Delta \Phi_{\mathrm{S}} / \Phi_{0} \|_{c} \\
(\%)\end{array}$ & $\begin{array}{c}\varepsilon_{\text {loc }} \|_{c} \\
(\%)\end{array}$ & $\begin{array}{c}Z \\
(\%)\end{array}$ & $\mathcal{L}$ \\
\hline $\mathrm{L}$ & 1003 & $716 / 709^{\star}$ & $34.9 / 33.1^{\star}$ & 50.3 & $68.8 / 65.5^{\star}$ & 0.62 \\
$\mathrm{~T}$ & 1019 & $786 / 803^{\star}$ & $29.3 / 27.5^{\star}$ & 44.6 & $63.3 / 57.4^{\star}$ & 0.67 \\
\hline
\end{tabular}

Table 2: Macroscopic properties extracted from the in-situ testing. $\varepsilon_{\mathbf{l o c}}=\ln \left(\frac{S_{0}}{S}\right)$ represents an average value of the true strain in the minimal cross-section which can be related to the direct measurement of area of the section reduction. $Z=\left(\frac{S_{0}-S}{S}\right)$ is the striction coefficient. $\mathcal{L}$ represents the Lankford coefficient defined as: $\mathcal{L}_{\|}=\varepsilon_{\perp}^{p} / \varepsilon_{\mathrm{S}}^{p}$. Blue $\left.{ }^{*}\right)$ represent values from the macroscale $\mathrm{NT}_{4}$ specimens, Shinohara et al. (2016). 
L-specimen

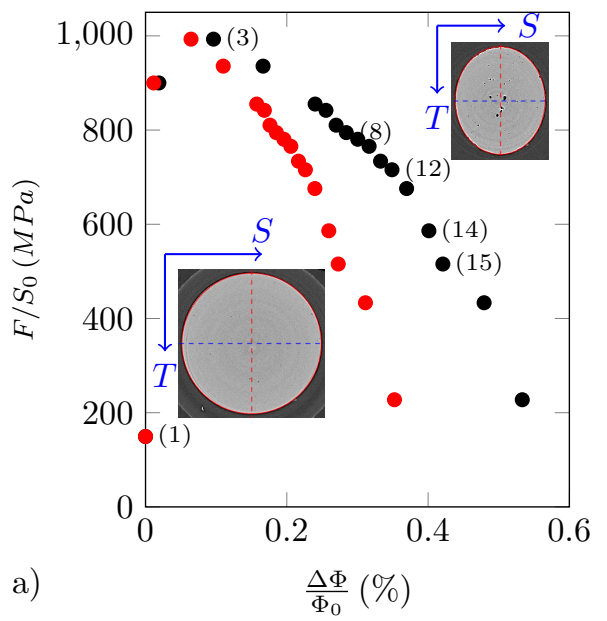

T-specimen

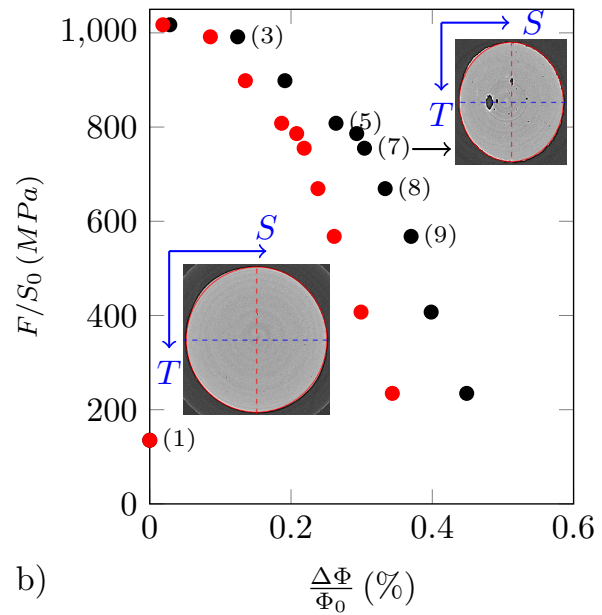

Figure 4: Evolution of Load vs diametral reductions in the minimal cross-section along $\mathrm{S}$ direction (black dots $\bullet$ ) and transverse direction ( $\mathrm{T}$ direction for $\mathrm{L}$-specimen and $\mathrm{T}$ direction for L-specimen: (red dots $\bullet$ ). 2D slices of the minimal cross-section are represented for the first scan and a deformed scan (index 12 for L-specimen and index 7 for T-specimen). Red Line represent the ellipse corresponding to the area of the minimal cross-section.

\subsection{Tomography microscopic observations}

The aim of this section is to identify the origins of the anisotropic fracture behavior with a particular focus on damage mechanisms. These will be assessed in a qualitative manner on $2 \mathrm{D}$ sections $3 \mathrm{D}$ visualisations of in-situ tomography data and final post mortem fractography.

\subsubsection{D damage observations}

L-specimen. Fig. 5 shows a $2 \mathrm{D}$ section of in-situ tomography data of the $\mathrm{L}$ loaded specimen. The section is normal to the loading direction and corresponds to the minimal net section of the sample ( $\mathrm{S}-\mathrm{T}$ plane). In the initial state only very few voids can be discerned. The CaS particles are hard to identify with the current tomography voxel size. However, they play an important role in the damage process as voids nucleate on these particles. In the subsequent loading steps (Fig. 5 b), c) and d)) axisymmetric void growth takes places mainly in the center of the specimen which is consistent with the location of the main driving forces of ductile damage, i.e. plastic strain and high levels of triaxial stress are concentrated in this region. Coalescence of large voids parallel to $\mathrm{L}$ direction is seen at the center of the sample after substantial growth. These last load steps (Fig. 5 e), f)) correspond to the "coalescence" part in the stress strain curve with an steeper stress decrease slope (see Fig. 4). The high damage tolerance of this steel becomes evident as stable cracking can be seen in this part of the damage process where an internal crack progresses toward the specimen surface. This also highlights the need of using in-situ tomography 
to identify these processes rather than in-situ surface observation that are not representative for the damage process. It may be noticed that the sample section reduces substantially in anisotropic manner as previously identified on larger specimens in Shinohara et al. (2016).

In Fig. 6 $2 \mathrm{D}$ sections in the $\mathrm{L}-\mathrm{T}$ plane in the center of the L-specimen are shown. The nucleated voids appear axisymmetric in this section. Some coalescence phenomena can be seen in Fig. 6 d). This load step is after the maximum load and the beginning of the accelerated coalescence phase as seen on the stress strain curves. Some roughness of the fracture surface is present, potentially linked to the heterogeneous distribution of large voids. The internal crack is linked to the sample surface through classical shear lips that are linked to the plane stress state of the sample surface, Fig. 6 f).

In Fig. 7. 2D sections in the L-S plane of the L-sample are given. The substantial width reduction of the sample can again be observed. Regarding the evolution of initial porosity, heterogeneous void growth is the main mechanism up to load step 12 (Fig. 7 d)). Moreover, the void distribution seems to be controlled by the particle distribution rather that only by the mechanical field of stress triaxiality and strain. Fig. 7 e) and f) show again the nucleation and propagation of an internal crack from the sample center to the sample surface. This occurs during the loading stages in which the force decreases rapidly (Fig. 4 a)). The crack is rough and shows a zig-zag pattern. In Fig.7p) and f) elongated and rotated voids are seen. They may be a result of the localization of strain bands Morgeneyer et al. (2016) and they may turn when they undergo simple shear, Roth et al. (2018).

Fig. 8 shows $2 \mathrm{D}$ sections along the line highlighted in Fig. 5 d) in the Lsample. This line was chosen to enhance the observation of the anisotropic damage mechanisms and in particular the longest void observed in this sample. Indeed, already for the initial state in Fig. 8 a) an elongated CaS particle cluster can be discerned (see inset). At maximum load, Fig. 8 b), voids have nucleated from these particle cluster. Necklace void growth and coalescence can be seen in step 5 ( Fig. 8 c). This anisotropic phenomenon was already discussed in Benzerga et al. (2004). A heterogeneous field of small aligned voids and large voids with diamond shape can be seen. Some large voids have coalesced through impingement. In this L loading configuration, the particle cluster does not play a very detrimental role as its contribution to the crack is rather limited. A different scenario will be seen in the following figures for loading normal to the clusters.

T-specimen. In Fig. 9, 2D views of the minimal cross-section are seen for the other loading (T-specimen) configuration. Here, the loading direction is normal to the rolling direction. Whilst in the initial section a) mostly spherical voids are seen, an elongated void in rolling direction becomes visible in step 3, Fig. 9 b). These voids cover an area that is substantially larger than that of the other voids. Mostly growth in $\mathrm{S}$ direction can be seen here but also some length increase in rolling direction is discerned. This void is very detrimental to the structural integrity of the sample. The origin of anisotropic ductility can now be 
explained by the premature growth of large voids in this loading configuration. Step 7 (Fig. 9 d) corresponds to the start of the increased force drop in the stress strain curve. Coalescence of the main void with an adjacent elongated void is seen. These two voids are not located in the center of the sample as it would be expected. Their eccentricity highlights the heterogeneous of microstructure and its influence on the damage process. In following sections this void covers large amounts of the cross section. Fig. 9 f) shows some sort of a damage ring in the upper right corner of the sample section. This is linked to the numerical 2D cutting of a shear lip that can be clearly identified in other sections in following figures. It may be noticed that, similar to the L-configuration, the material is tolerant to the damage and fractures stably during the step load decrease.

In Fig. 10, no clear evidence of damage anisotropy is seen in the geometrical mid-section. A mixture of large and small voids is present. The internal crack progresses from large voids via small secondary voids. In the end, a shear lip is formed in Fig. 10 f).

Fig. 11 shows sections in the T-S sample midplane of the T-sample. Here, a cut through the large anisotropic void can be seen on the left. The strong diamond shaped growth of the growing void is interesting, see Fig. 11 b). The clear heterogeneous void growth and detrimental nature of this void is again evident. Coalescence with a smaller void is seen in step 7. From this void cluster, a crack progression is then seen towards the right part of the sample in step 8, Fig. 11d). This progression occurs via reduced void growth on small voids. The strong inclination of the crack makes think again of localized underlying strain bands Morgeneyer et al. (2016). It is clear that the anisotropic large void, as pointed on, plays a mayor role in the damage process thereby explaining the fracture anisotropy of the material.

In Fig. 12, a 2D cut through the elongated void is shown as indicated in Fig. 9 c) to better highlight its growth in L direction. The opening of the void and the strain localization between the void and the sample surface can be imagined from these sections. Coalescence with the specimen surface via shear lips is seen in Fig. 10 e) and f). This void governs the damage process in the T-loaded sample.

\subsubsection{D damage visualizations}

It has become evident in the previous figures that the damage process is highly three dimensional, heterogeneous and driven by the weakest feature in the microstructure that, even if they can appear in a very small fraction, they seem to have a major effect on the fracture anisotropy. The particle distribution is hence of primary importance. To highlight the 3D damage evolution further, the damage features have been segmented and are shown in Fig. 13. The sample surface is made half transparent and the steel matrix transparent. In this view along the $\mathrm{S}$ axis for the L loading specimen, some elongated features are seen as previously in the $2 \mathrm{D}$ sections. The final crack (shown in yellow) coalesces with the elongated void in the loading direction, but as mentioned earlier, this configuration is not very detrimental. Fig. 14 shows a 3D representation of the damage along the loading direction L. It can be seen that the void growth is 
mostly concentrated in the sample center. However, le largest damage feature is not in the center. This is linked to the particle distribution in the sample. In the $3 \mathrm{D}$ visualization of the $\mathrm{T}$ loaded specimen, Fig. 15, elongated features are visible in the rolling direction. The dominance of the elongated void on the fracture process is again evident. It is seen that only few elongated features are present though. In Fig. 16 a 3D representation of the voids normal to the loading direction is seen for the T loaded specimen. Nucleation of voids on the particle clusters is seen in Fig. 16 b) in the lower part of the image. These clusters are rather few but grow very fast in subsequent load steps (Figs. 16 c) and $\mathrm{d})$ ).

To compare in-situ tomography observation with classical post mortem fractography Fig. 17 shows 3D representations of voids for the $\mathrm{T}$ sample a) and the $\mathrm{T}$ samples b). The damage features on the fracture surface seem rather isotropic. Large and small dimples can be seen. The damage anisotropy is substantially clearer int he tomography representations. The elongated void for the T loading can be seen on the fracography but its neighbouring anisotropic void is hard to discern in fractography. As post mortem fractography only shows the final damage state, the early anisotropic voids growth for the T sample is obfuscated.

\subsection{Tomography quantitative damage measurement}

The aim of this section is to quantify the origins of the anisotropic fracture behavior. Here, the entire notch area was selected for damage quantification and the measurement of the size of the $N$ largest cavities was used to quantify the void growth, Maire et al. (2008). Particle tracking was not performed, but another analysis based on finite element simulation is proposed in the second paper. During the deformation, the volume of analysis was growing due to void growth and associated volume change: from $0.82 \mathrm{~mm}^{3}$ to $0.88 \mathrm{~mm}^{3}$ and slighlty different for the two specimens.

Void nucleation. The number of particle/void density, which is obviously resolution dependent was counted for each step and plotted as a function of the radial contraction $\Delta \Phi_{\mathrm{S}} / \Phi_{0} \|_{c}$ (Fig. 18 a) and b)). As expected, the number of voids grew as the loading increases except during coalescence after the load drop for $\mathrm{L}$ loading direction. The initial fraction of porosity is higher for $\mathrm{T}$ direction ( $f_{0}=4.210^{-4}$ versus $f_{0}=2.610^{-4}$ for $\mathrm{L}$ direction) whereas on Fig. $18 \mathrm{c}$ ) the same evolution of fraction of porosity ratio $f / f_{0}$ was observed at the beginning and for small deformation until $\Delta \Phi_{\mathrm{S}} / \Phi_{0}=10 \%$ corresponding to the maximum load. Then the ratio $f / f_{0}$ was growing (highest for $\mathrm{T}$ loading direction) with an acceleration close to the onset of coalescence for the both specimens. It can be noticed that the main void during the last steps -steps 16 and 17 for L loading and step 11 for T loading- is connected to the outer surface, which leads to a decrease of the inner porosity. In the next analysis, these points been removed from the plots. A statistical analysis (see appendix for more details) of the equivalent diameter $D_{e q}$ shows a decrease of the smallest void population as the loading increased in favour of large ones (for instance the maximum value 
of $D_{e q}=15 \mu \mathrm{m}$ at step 1 growing to $D_{e q}=63.2 \mu \mathrm{m}$ at step 12 the onset of coalescence for $\mathrm{L}$ direction).

Void growth. The evolution of $N$ largest particles (normalised mean equivalent diameter $\left.D_{e q} / D_{e q} \|_{0}\right)$ whithin the notched area were quantified and compared to the average diameter of the entire population in Fig. 19 for $\mathrm{L}$ and $\mathrm{T}$ loading conditions (the latest steps have not been taken into acount as explained before). As expected (Maire et al. (2008)), the mean equivalent diameter computed using the entire population remains almost constant due to the nucleation of new cavities. The evolutions using $N=20$ or $N=50$ largest cavities show the same trends, an increase of the void growth with an acceleration close to the end of the test. It corresponds to the value of "critical" diameter reduction $\Delta \Phi_{\mathrm{S}} / \Phi_{0} \|_{c} \%$ which is constistent with previous results, Landron et al. (2011). The void growth is higher for $\mathrm{T}$ loading which leads to a lower ductility. The "critical" value of the growth ratio at the onset of coalescence $D_{e q} / D_{e q 0} \|_{c}$ seems to not depend on the loading direction and is closed to 2.5 for $N=20$.

Void shape. The evolution of the Feret's shape factor of the $N=20$ largest particules during the in-situ tests for each loading direction is plotted in Fig. 20 . The aspect ratio was close to 0.65 (average value of all population, see appendix for statistical results) at the beginning which indicates that the shape is a more or less spherical. This ratio decreases significantly for both loading directions at the beginning until $\Delta \Phi_{\mathrm{S}} / \Phi_{0}=20 \%$ of deformation to reach 0.3 for $\mathrm{L}$ loading and 0.4 for $\mathrm{T}$ loading. This result indicates a higher elongation of the voids for the L loading direction. Distributions for all porosities of shape factor with respect to the volume size confirm this conclusion (see appendix). Fig. 21 illustrates an example of tracking the shape of void for each specimen. For L loading, a roughly spherical shape becomes ellipsoidal after deformation. For T loading, the elongated void illustrated in Fig. 12 shows an increase of the aspect ratio due to the opening of the void in the lateral direction corresponding to the loading. However, the use of the ratio of the smallest to the largest dimension of Feret's shape factors has some limitations since the notion of the loading and material direction disappears. A complementary analysis is proposed based on morphological mass distribution parameters which allows to compute the orientation of voids ( $\gamma$ angle as explained in section 2.5) with respect to the principal axis of the equivalent ellipsoid and the material $\mathrm{L}$ direction. The adimensionnal principal moments of inertia $\lambda_{2}$ versus $\lambda_{1}$ of the 50 largest individual voids are plotted in Figs. 22 to 25 (see also Appendix C for complementary steps) to describe the shapes whithin a triangle having original properties. At the triangle vertices, we can distinguish a mass distribution related to 3D objects: spherical, flat and needle. Between these limits, shapes vary continuously. The distribution of the 50 largest individual voids for both specimen is situated close to the spherical vertice at step 1 (more evidence for L loading). After deformation (Step 5, step 10 and step 13), the distribution of L loading becomes in the prolate ellipsoid-typed triangle edge with some flat ellipse-typed shape (the most 
important cavities). For T loading, the distribution evolves after deformation between prolate-ellipsoid typed and oblate ellipsoid-typed.

Void orientation. Figs. 22 to 25 describe the evolution of the distribution (50 largest individual particules) of the $\gamma$ angle between the principal axis of the equivalent ellipsoid and the material $\mathrm{L}$ direction. $\gamma=0$ therefore corresponds to a cavity oriented along the $\mathrm{L}$ direction (see also Appendix C for complementary steps). A polar plot is used to represent $\gamma$ angle distribution wherein radial component represents the distance from the center of the minimal cross-section of the sample (the marker size is related to the volume size of the void). For L specimen, $\gamma$ angle have no particular orientation at first for the 50 largest voids. $\gamma$ becomes quickly oriented parallel to the loading direction L. For steps 5 and 10, peaks are clearly visible on the histograms for values close to 0 and 180 degrees. The latest steps are characterized by the larger voids which coalescence perpendicular to the loading direction (see insert in Fig. C.32). For the T direction (see Figs. 24 to 25), the particles are initially aligned in the L direction. The larger void (in yellow from step 3 ) is clearly oriented according to the $\mathrm{L}$ direction $\left(\gamma=15^{\circ}\right)$. This is also the case for the largest cavities (see red insert in step 5) even if cavities oriented according to the loading direction $\mathrm{T}$ appear as the loading increases (see orange insert in step 5 and the peak around $\gamma=90^{\circ}$ of the histograms). These quantitative analysis are consistent with the qualitative observations.

\section{Conclusions}

The origin of fracture anisotropy in a modern X100 steel was investigated using in-situ X-ray tomography. In-situ tensile tests have been performed at room temperature on notched tensile round specimens extracted from a heavy plate both along the rolling and the transverse directions. The in-situ data allowed quantifying both macroscopic deformation and microscopic damage parameters such as porosity, void shape and void orientation. Deformation anisotropy was studied by direct measurement of lateral reductions of the minimal section. The material exhibits an increased strain along the short transverse direction $\mathrm{S}$, more pronounced for the L-loading direction, as it was observed at macroscopic scale.

Anisotropic damage mechanisms are clearly identified associated with a limited fraction of elongated and aligned $(\mathrm{CaS} / \mathrm{TiN})$ particles in rolling direction. For loading in L direction elongated voids in rolling direction nucleate from these particles and coalesce in necklace form. In contrast, for loading in transverse direction the void nucleation on elongated particles led to premature void growth generating large voids. This void nucleation and growth anisotropy caused a reduced ductility for $\mathrm{T}$ loading. The increased void growth kinetics for $\mathrm{T}$ loading was assessed via quantifying the growth by the $N$ largest voids. Growth of elongated particules along the $\mathrm{L}$ direction were detected by calculating morphological features and Euler's angles void orientation.

In-situ tomography thereby shows advantages over classical fractography as fractographic observations did not reveal anisotropic damage mechanisms. This 
is linked to the size distribution of the anisotropic clusters of particles that are few in this material. A three-dimensional analysis is needed to identify these particle clusters and their distribution in space. The current in-situ study revealed that the few anisotropic particle clusters play a mayor role in the damage evolution and that they represent the weakest point in the microstructure in particular for loading normal to the aligned cluster. Indeed, the premature nucleation and growth led to a big void with diamond section caused reduced strain to fracture for the $\mathrm{T}$ loaded specimen.

\section{Acknowledgement}

The authors gratefully acknowledge Nippon Steel Corporation for supporting, M. Dimichiel for help in the use of the beamline at the ESRF (experiment ma1932) and Mateis team from INSA-Lyon university for the use of in-situ test machine.

\section{Conflict of interest}

On behalf of all authors, the corresponding author states that there is no conflict of interest.

\section{References}

T. F. Morgeneyer, J. Besson, H. Proudhon, M. Starink, I. Sinclair, Experimental and numerical analysis of toughness anisotropy in AA2139 al-alloy sheet, Acta Materialia 57 (2009) 3902-3915.

J. Chen, Y. Madi, T. Morgeneyer, J. Besson, Plastic flow and ductile rupture of a 2198 al-cu-li aluminum alloy, Computational Materials Science 50 (2011) $1365-1371$.

B. Kondori, Y. Madi, J. Besson, A. Benzerga, Evolution of the 3d plastic anisotropy of hcp metals: Experiments and modeling, International Journal of Plasticity (2018).

J. S. Herrington, Y. Madi, J. Besson, A. A. Benzerga, Modeling the 3d plastic anisotropy of a magnesium alloy processed using severe plastic deformation, in: V. V. Joshi, J. B. Jordon, D. Orlov, N. R. Neelameggham (Eds.), Magnesium Technology 2019, Springer International Publishing, Cham, 2019, pp. 283-287.

A. A. Benzerga, Rupture ductile des tôles anisotropes. Simulation de la propagation longitudinale dans un tube pressurisé, Ph.D. thesis, Ecole des Mines de Paris, 2000. Thèse de doctorat dirigée par Pineau, André Physique. Science des matériaux. Rhéologie Paris, ENMP 200. 
Y. Shinohara, Y. Madi, J. Besson, Anisotropic ductile failure of a high-strength line pipe steel, International Journal of Fracture 197 (2016) 127-145.

F. Bron, J. Besson, A yield function for anisotropic materials. Application to aluminium alloys, Int. J. Plasticity 20 (2004) 937-963.

A. Benzerga, J. Besson, A. Pineau, Anisotropic ductile fracture Part I: experiments, Acta Mater. 52 (2004) 4623-4638.

T. Pardoen, Ductile Fracture of Cold-Drawn Copper Bars: Experimental Investigation and Micromechanical Modelling, Ph.D. thesis, Université catholique de Louvain, Belgium, 1998.

E. Maire, S. Zhou, J. Adrien, M. Dimichiel, Damage quantification in aluminium alloys using in situ tensile tests in x-ray tomography, Engineering Fracture Mechanics 78 (2011) 2679 - 2690.

C. Landron, E. Maire, O. Bouaziz, J. Adrien, L. Lecarme, A. Bareggi, Validation of void growth models using X-ray microtomography characterization of damage in dual phase steels, ACTA MATERIALIA 59 (2011) 7564-7573.

H. Pommier, E. Busso, T. Morgeneyer, A. Pineau, Intergranular damage during stress relaxation in AISI 316L-type austenitic stainless steels: effect of carbon, nitrogen and phosphorus contents, Acta Materialia 103 (2016) 893-908.

F. Hannard, A. Simar, E. Maire, T. Pardoen, Quantitative assessment of the impact of second phase particle arrangement on damage and fracture anisotropy, Acta Materialia 148 (2018) 456 - 466.

A. Buljac, M. Shakoor, J. Neggers, M. Bernacki, P. O. Bouchard, L. Helfen, T. F. Morgeneyer, F. Hild, Numerical validation framework for micromechanical simulations based on synchrotron 3D imaging, Computational Mechanics 59 (2017) 419-441.

B. Tanguy, T. Luu, G. Perrin, A. Pineau, J. Besson, Plastic and damage behavior of a high strength X100 pipeline steel: experiments and modelling, Int. J. of Pressure Vessels and Piping 85 (2008) 322-335.

E. Tsuru, Y. Nagata, Y. Shinohara, J. Agata, S. Shirakami, Forming and Buckling Simulation on High-strength UOE Pipe with Plastic Anisotropy, Technical Report, Nippon Steel Technical Report Nº 102 January 2013, 2013.

Y. Shinohara, Prestrain effect on anisotropic ductile damage, Ph.D. thesis, Mines ParisTech, 2014.

M. Di Michiel, J. M. Merino, D. Fernandez-Carreiras, T. Buslaps, V. Honkimäki, P. Falus, T. Martins, O. Svensson, Fast microtomography using high energy synchrotron radiation, Review of Scientific Instruments 76 (2005) 043702. 
Y. Madi, J. M. Garcia, H. Proudhon, H. Lukas, Y. Shinohara, J. Besson, T. Morgeneyer, A Dataset for In-situ synchrotron tomography experiments to investigate anisotropic damage of line pipe steel, Dataset on Zenodo, doi:10.5281/zenodo.3528199, 2019.

J.-Y. Buffière, E. Maire, J. Adrien, J.-P. Masse, E. Boller, In Situ experiments with $\mathrm{X}$ ray tomography: an attractive tool for experimental mechanics, Exp. Mech. 50 (2010) 289-305.

E. Jones, T. Oliphant, P. Peterson, et al., SciPy: Open source scientific tools for Python, 2001-. [Online; accessed jtoday i.].

C. Landron, E. Maire, J. Adrien, O. Bouaziz, M. Di Michiel, P. Cloetens, H. Suhonen, Resolution effect on the study of ductile damage using synchrotron X-ray tomography, Nuclear Instruments \& Methods in Physics Research Section B-Beam Interactions with Materials and Atoms 284 (2012) $15-18$.

W. H. Walton, Feret's statistical diameter as a measure of particle size, Nature 162 (1948) 329-330.

H. G. Merkus, Particle Size Measurements: Fundamentals, Practice, Quality (Particle Technology Series Book 17), Springer, 2009.

E. P. Denis, C. Barat, D. Jeulin, C. Ducottet, 3d complex shape characterization by statistical analysis: Application to aluminium alloys, Materials Characterization 59 (2008) $338-343$.

A. Borbély, F. Csikor, S. Zabler, P. Cloetens, H. Biermann, Three-dimensional characterization of the microstructure of a metalmatrix composite by holotomography, Materials Science and Engineering: A 367 (2004) 40 - 50.

T. F. Morgeneyer, T. Taillandier-Thomas, A. Buljac, L. Helfen, F. Hild, On strain and damage interactions during tearing: $3 \mathrm{~d}$ in situ measurements and simulations for a ductile alloy (AA2139-t3), Journal of the Physics and Mechanics of Solids 96 (2016) 550-571.

C. C. Roth, T. F. Morgeneyer, Y. Cheng, L. Helfen, D. Mohr, Ductile damage mechanism under shear-dominated loading: In-situ tomography experiments on dual phase steel and localization analysis, International Journal of Plasticity 109 (2018) 169-192.

T. F. Morgeneyer, T. Taillandier-Thomas, A. Buljac, L. Helfen, F. Hild, On strain and damage interactions during tearing: $3 \mathrm{~d}$ in situ measurements and simulations for a ductile alloy (AA2139-t3), Journal of the Physics and Mechanics of Solids 96 (2016) 550-571.

E. Maire, O. Bouaziz, M. Di Michiel, C. Verdu, Initiation and growth of damage in a dual-phase steel observed by X-ray microtomography, Acta Materialia 56 (2008) 4954-4964. 


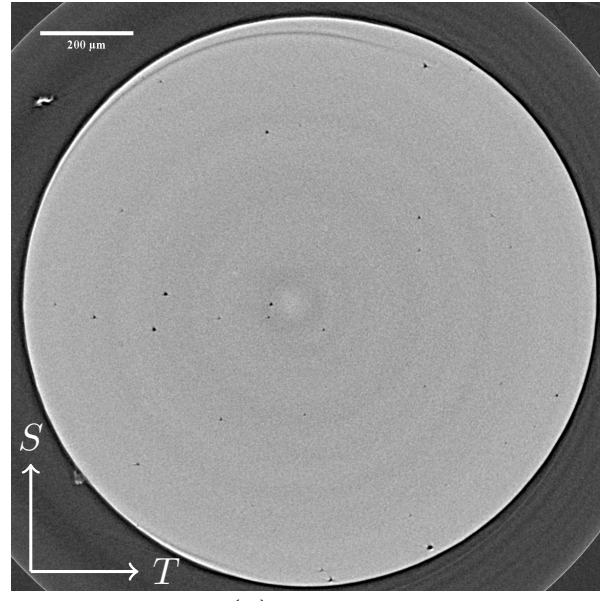

(a) Step 1

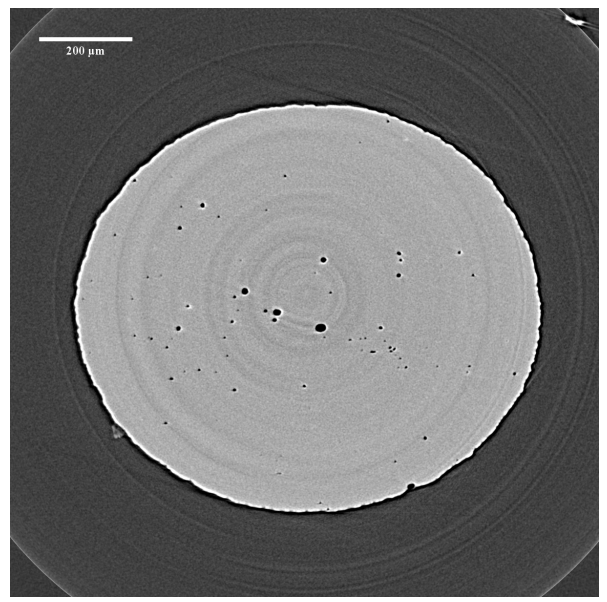

(c) Step 8

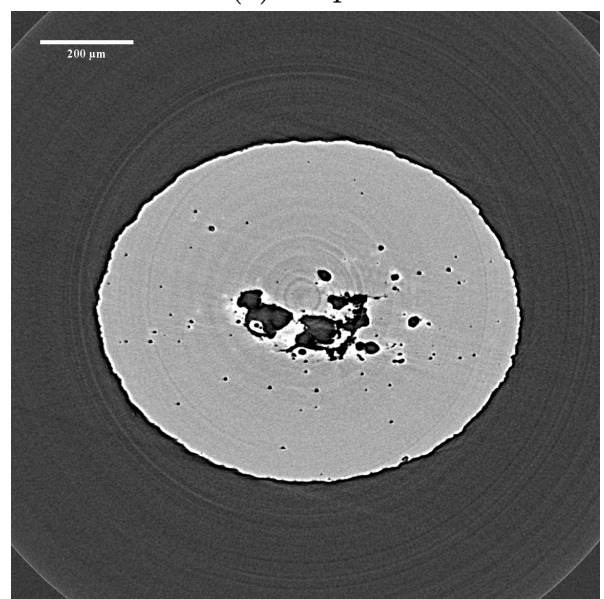

(e) Step 14

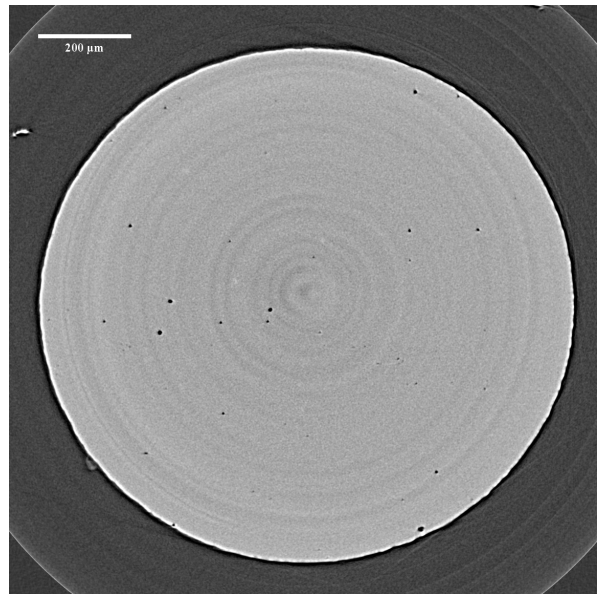

(b) Step 3

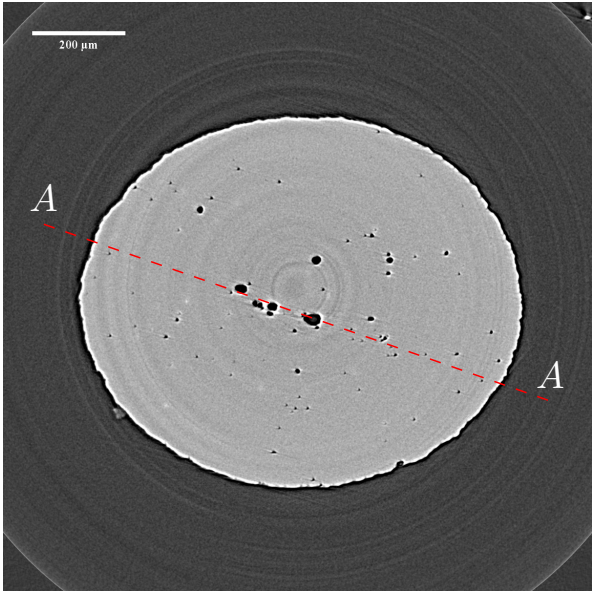

(d) Step 12

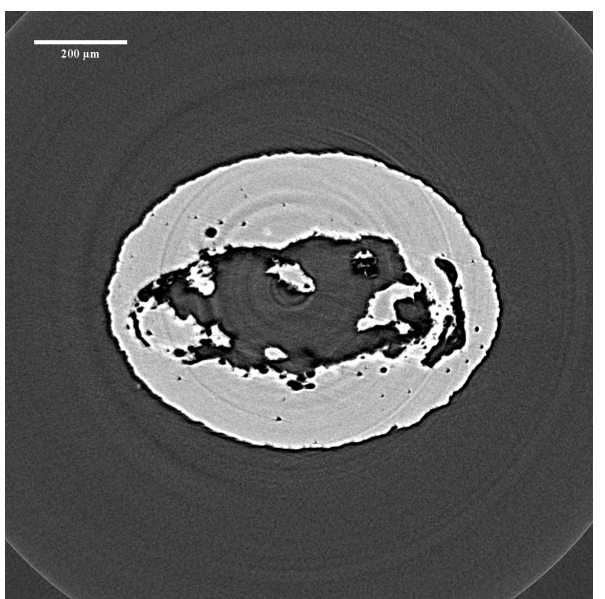

(f) Step 16

Figure 5: L-specimen: $2 \mathrm{D}$ slices $\left(\mathrm{TS}_{1}\right.$ plane) in the minimum cross section. 


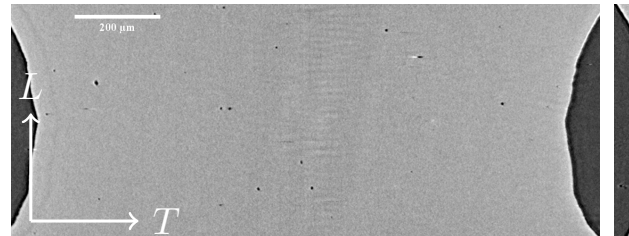

(a) Step 1

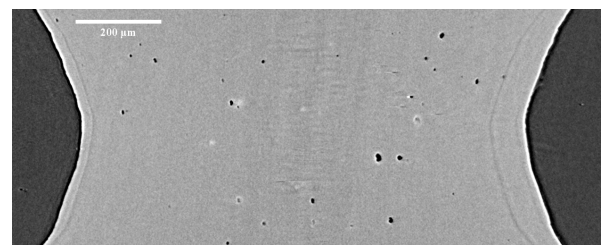

(c) Step 5

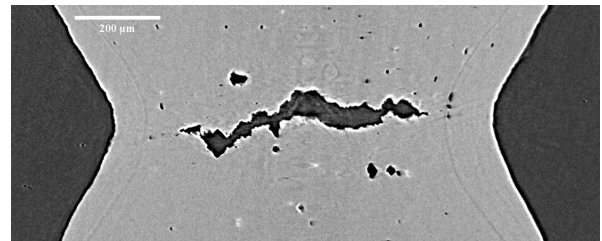

(e) Step 15

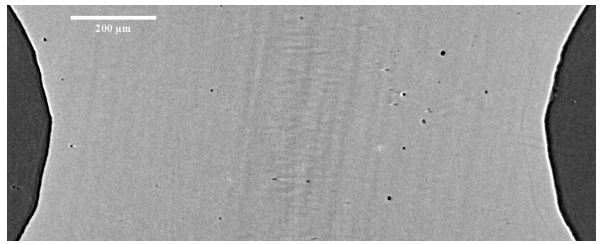

(b) Step 3

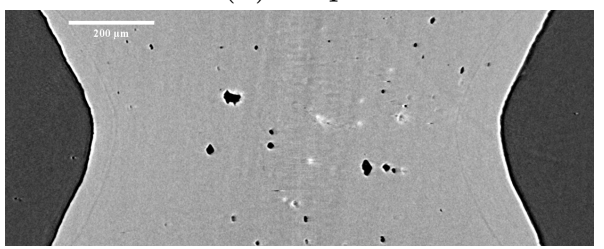

(d) Step 12

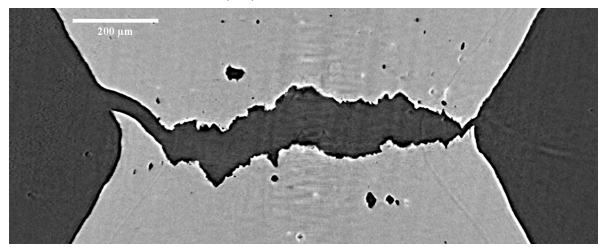

(f) Step 17

Figure 6: L-specimen: 2D slices (LT plane) in the mid-section. 


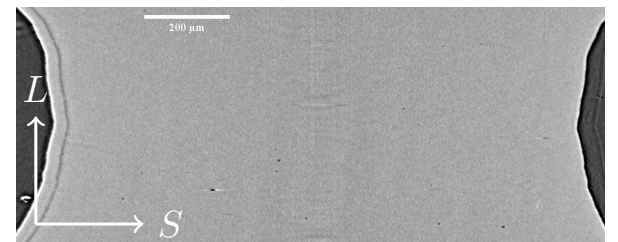

(a) Step 1

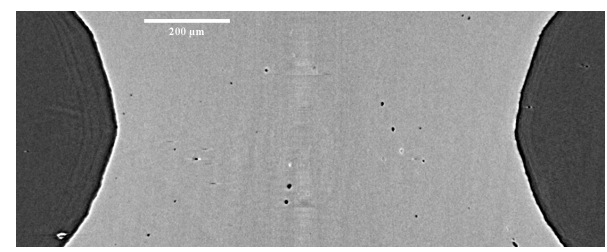

(c) Step 5

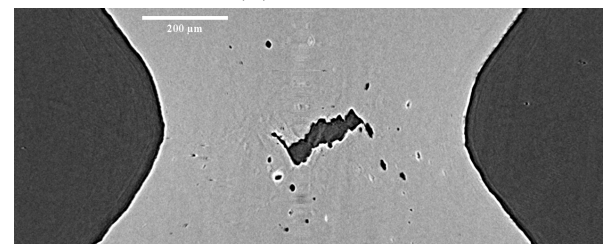

(e) Step 15

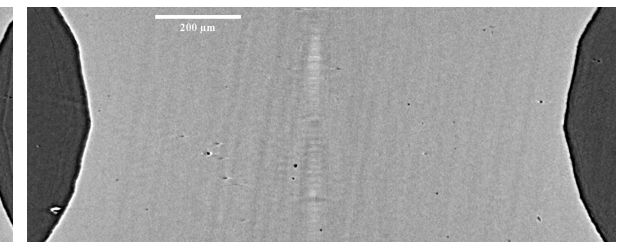

(b) Step 3

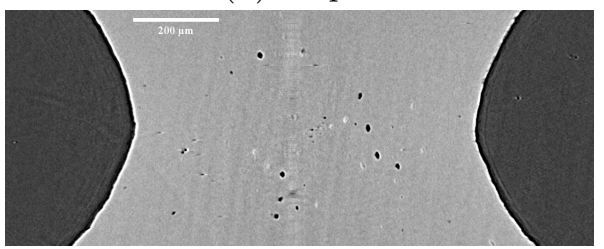

(d) Step 12

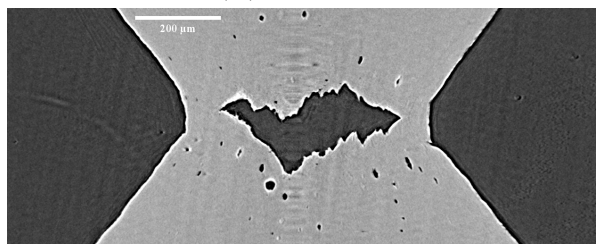

(f) Step 17

Figure 7: L-specimen: 2D slices (LS plane) in the mid-section. 


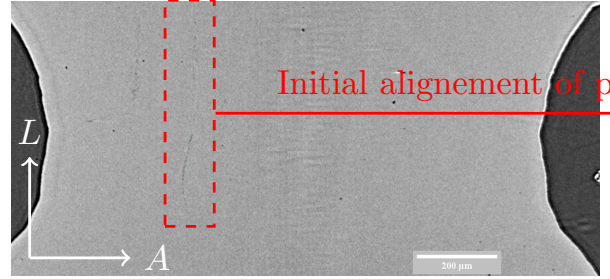

(a) Step 1

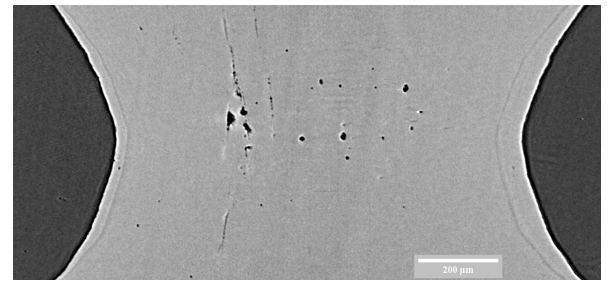

(c) Step 5

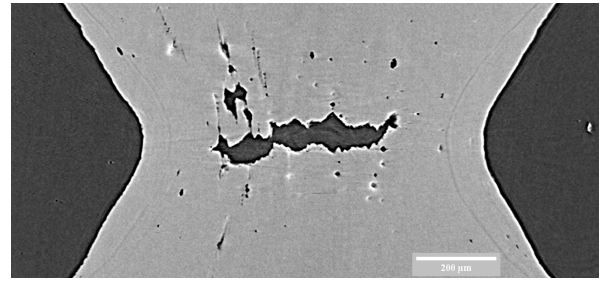

(e) Step 15

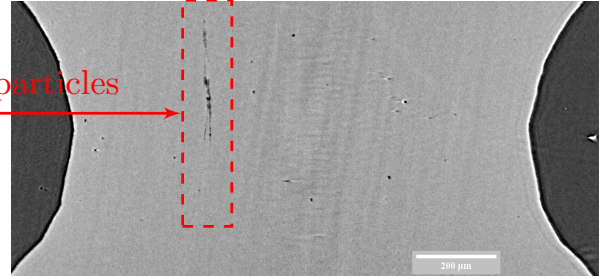

(b) Step 3

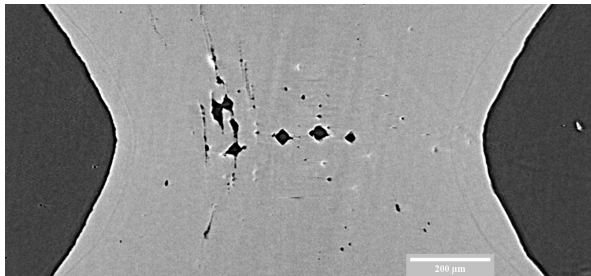

(d) Step 12

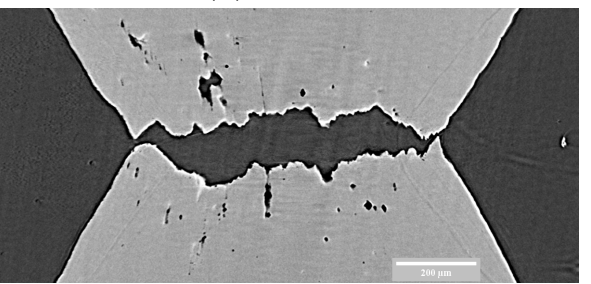

(f) Step 17

Figure 8: L-specimen: 2D slices (LA plane) whithin the elongated particules are located. Inset show a closeup ciew of the elongated particles cluster. 


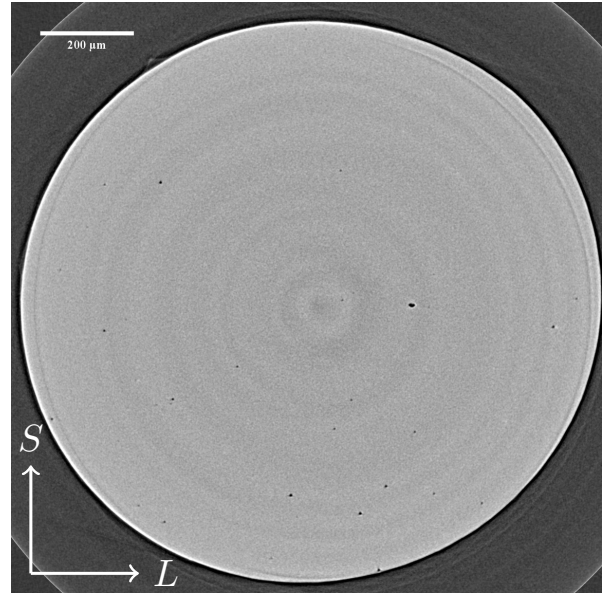

(a) Step 1

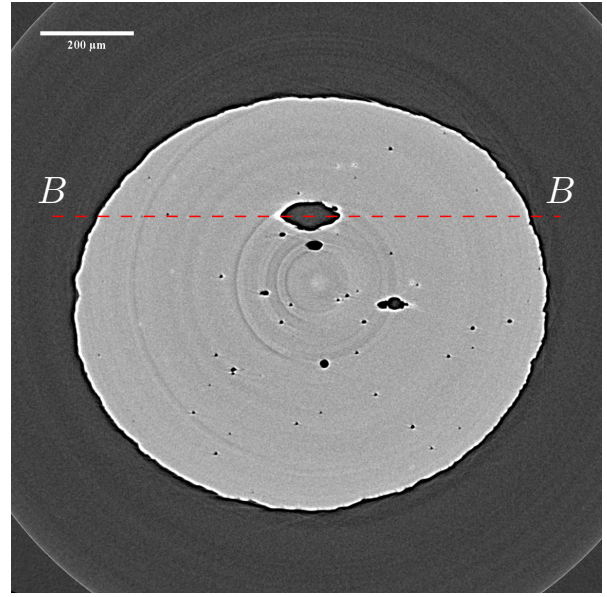

(c) Step 5

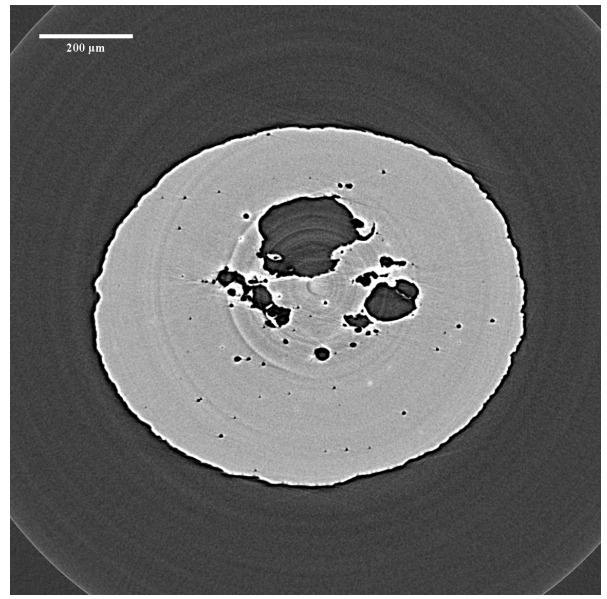

(e) Step 9

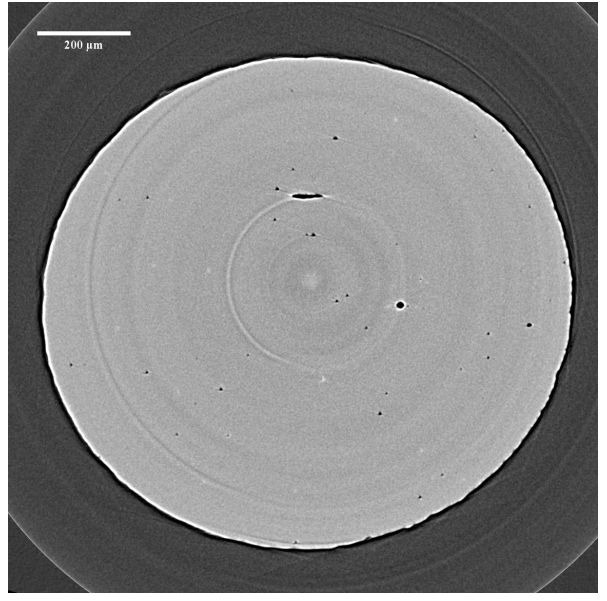

(b) Step 3

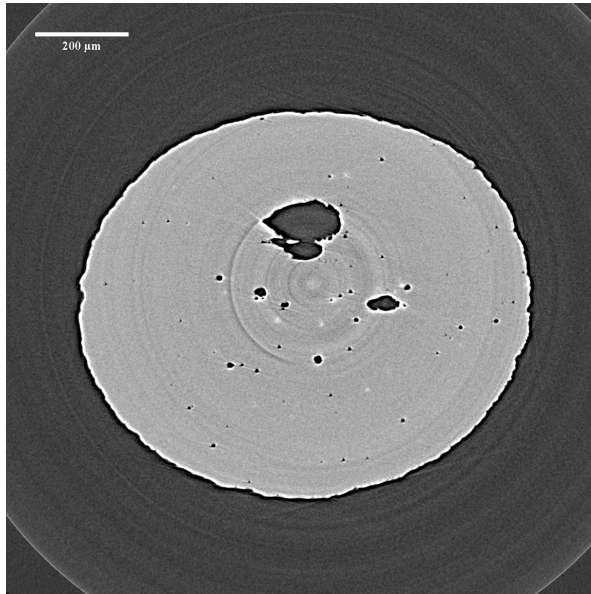

(d) Step 7

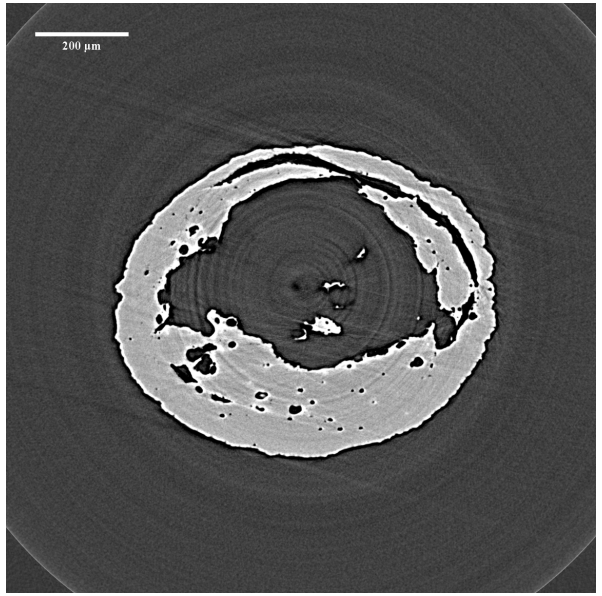

(f) Step 11

Figure 9: T-specimen: 2D slices (LSTlane) in the minimum cross section. 


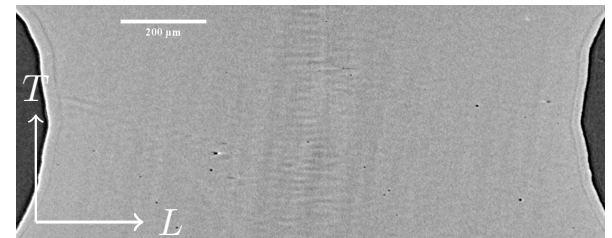

(a) Step 1

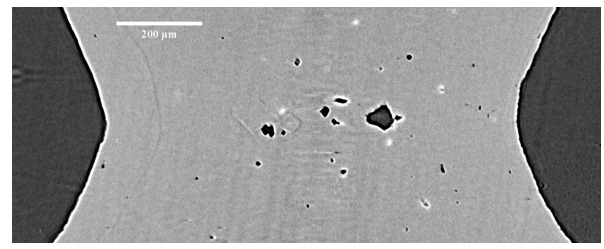

(c) Step 7

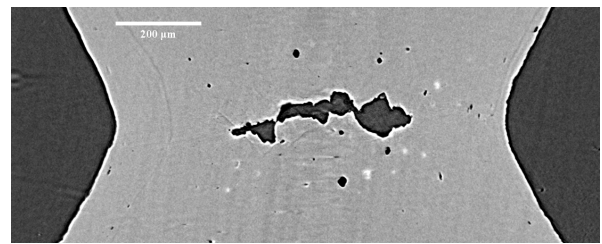

(e) Step 9

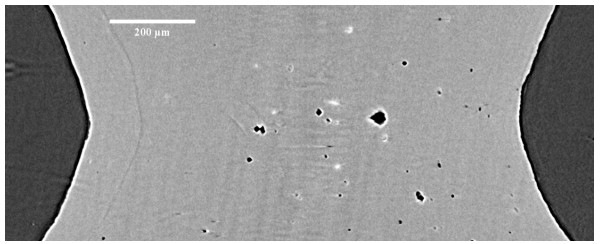

(b) Step 5

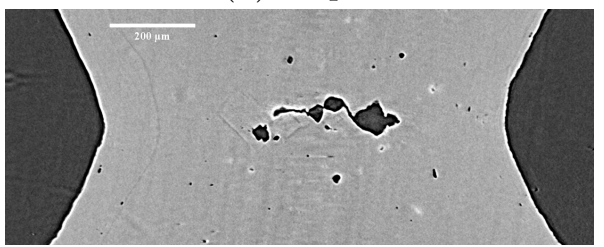

(d) Step 8

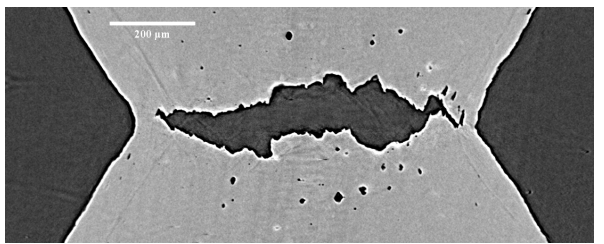

(f) Step 11

Figure 10: T-specimen: 2D slices (TL plane) in the mid-section. 


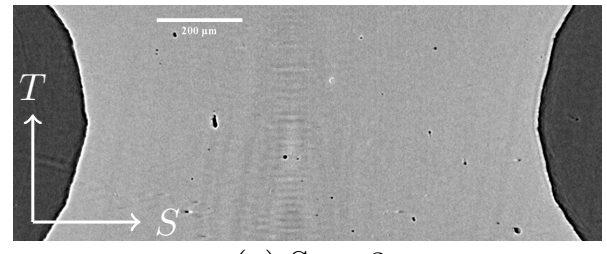

(a) Step 3

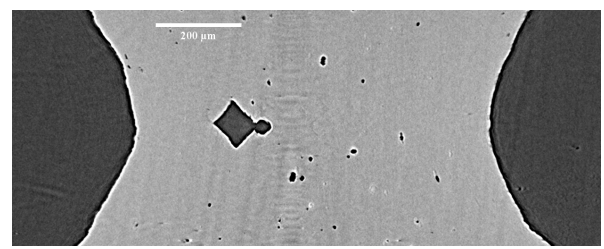

(c) Step 7

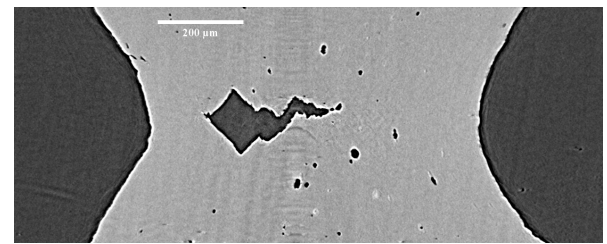

(e) Step 9

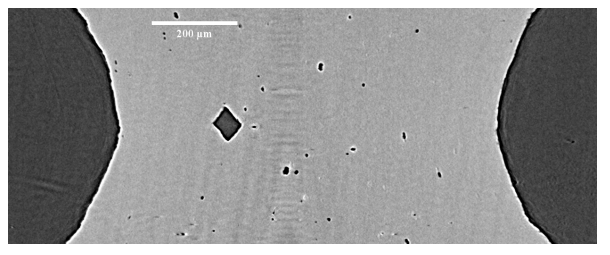

(b) Step 5

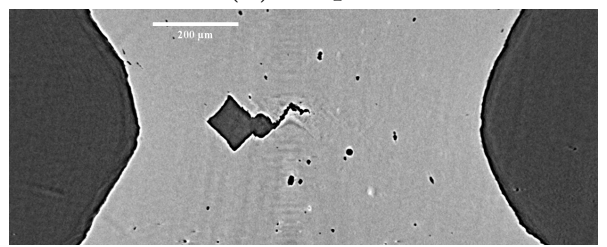

(d) Step 8

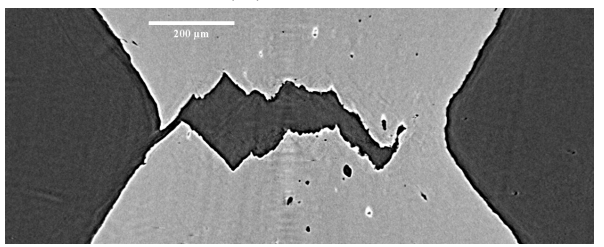

(f) Step 11

Figure 11: T-specimen: 2D slices (TS plane) in the mid-section. 


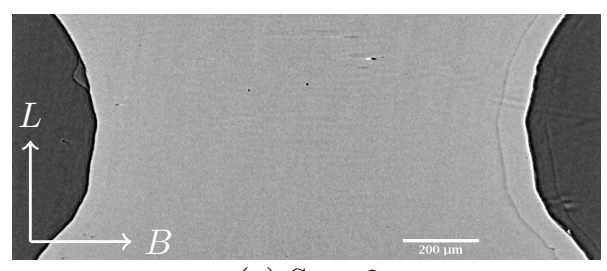

(a) Step 2

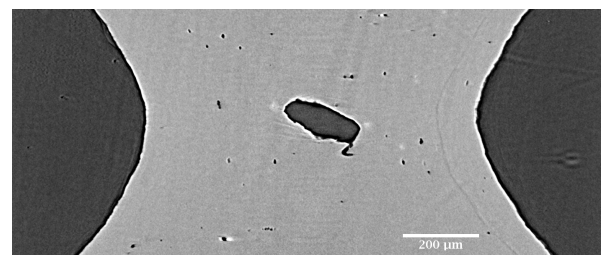

(c) Step 7

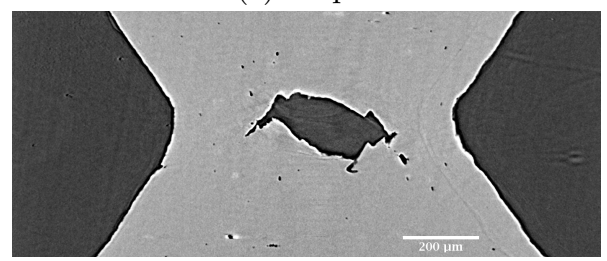

(e) Step 10

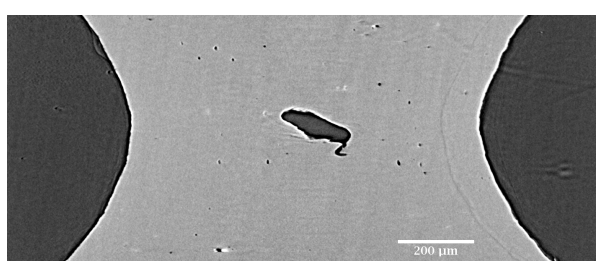

(b) Step 5

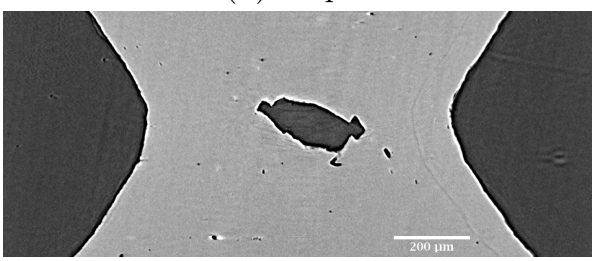

(d) Step 9

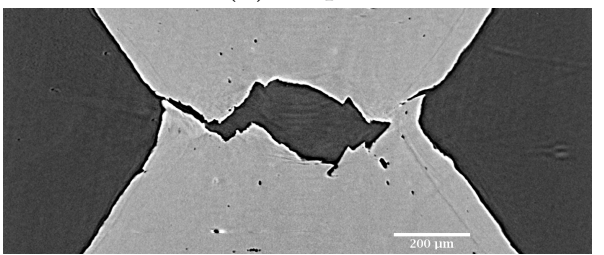

(f) Step 11

Figure 12: L-specimen: 2D slices (TB plane) whithin the elongated particule is located. 


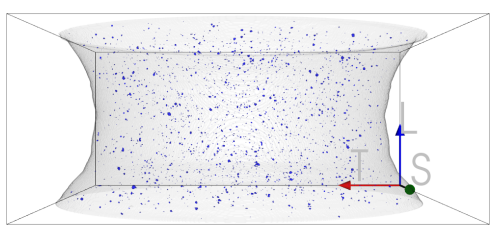

(a) Step 1

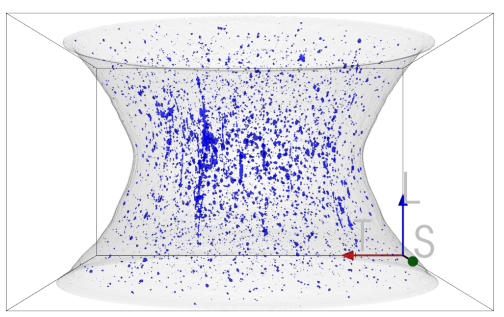

(c) Step 10

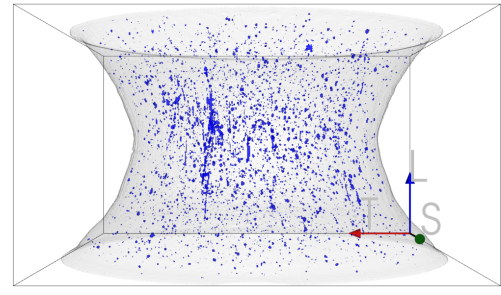

(b) Step 5

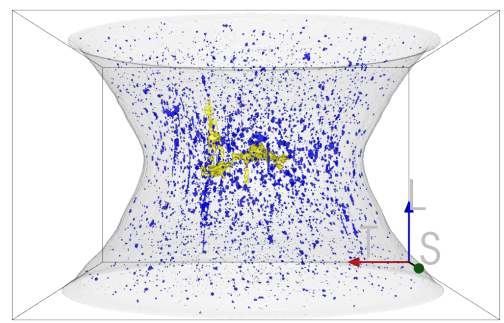

(d) Step 13

Figure 13: L-specimen: 3D vizualizations, vue of the TL plane. 


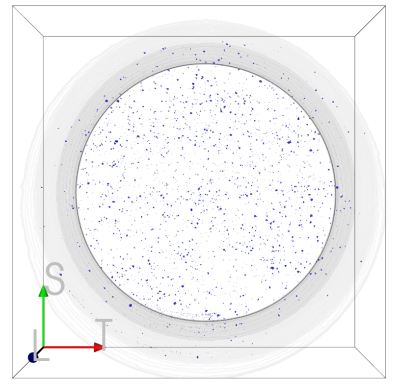

(a) Step 1

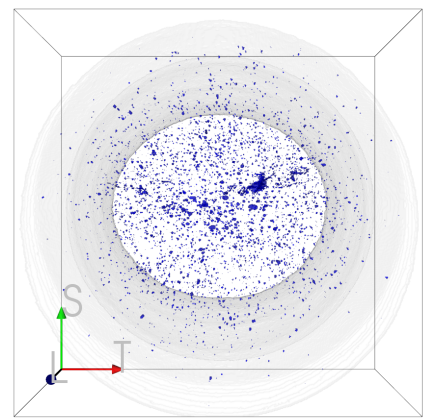

(c) Step 10

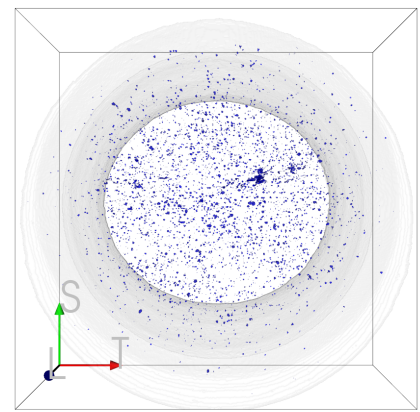

(b) Step 5

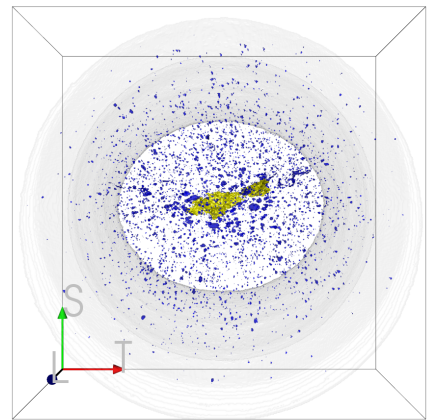

(d) Step 13

Figure 14: L-specimen: 3D vizualizations, vue of the TS plane. 


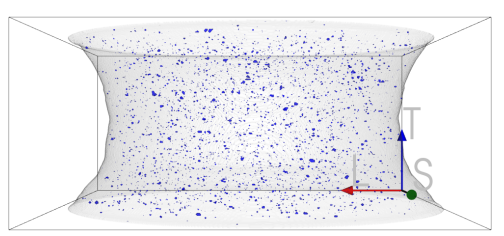

(a) Step 1

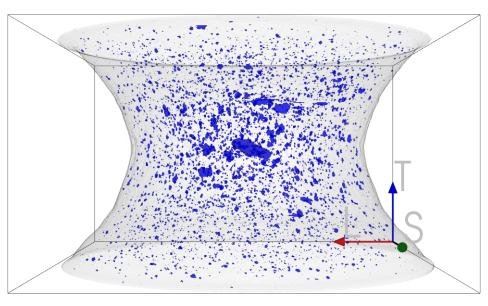

(c) Step 5

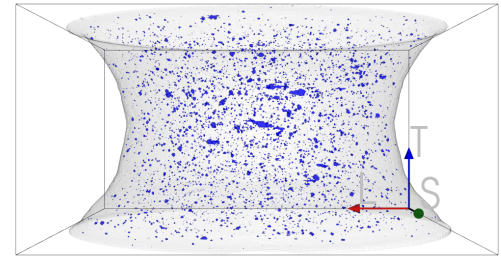

(b) Step 3

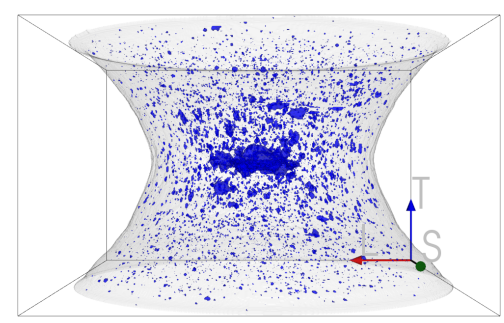

(d) Step 8

Figure 15: T-specimen: 3D vizualizations, vue of the TL plane. 


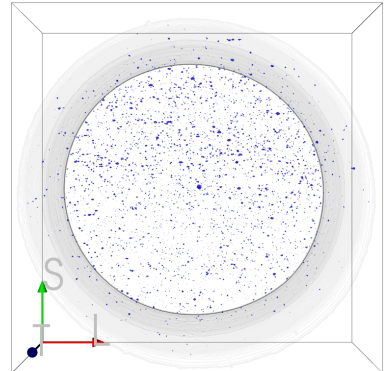

(a) Step 1

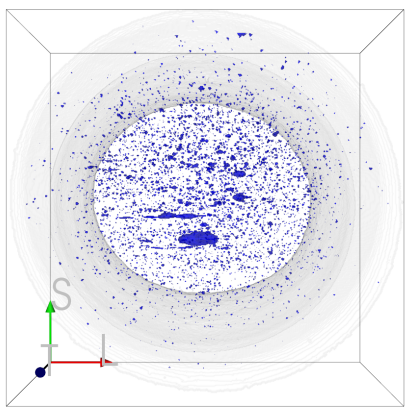

(c) Step 5

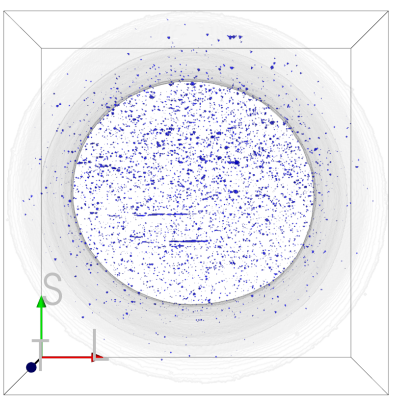

(b) Step 3

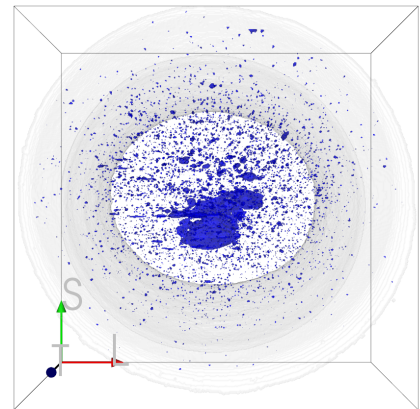

(d) Step 8

Figure 16: T-specimen: 3D vizualizations, vue of Fig. 12 he LS plane. 

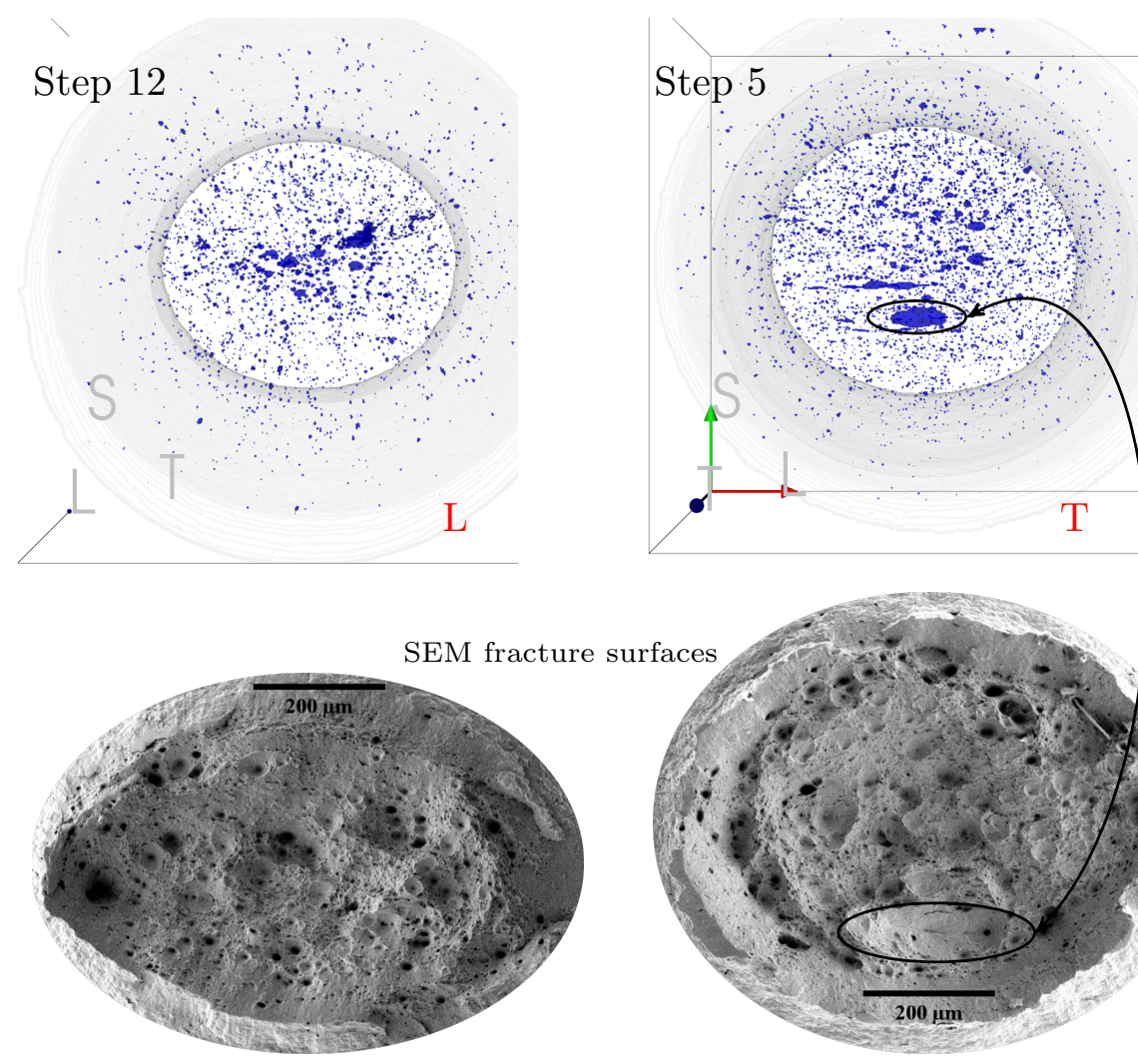

(a) L-specimen

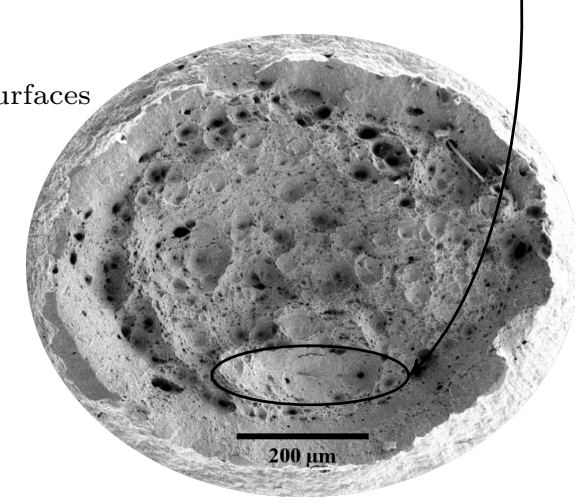

(b) T-specimen

Figure 17: Comparison of L-loading direction (a) vs T-loading direction (b): 3D vizualizations perpendicular to the loading direction (just before the load drop) and SEM fractures surfaces. 


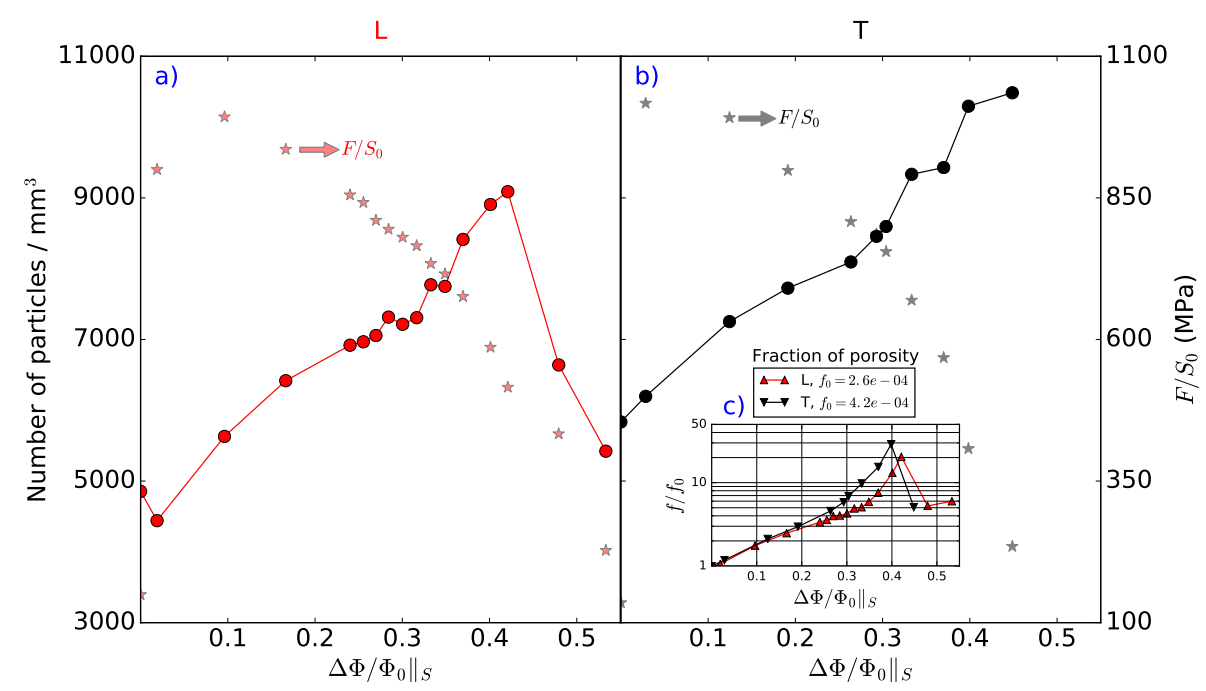

Figure 18: a) and b): Evolution of the total number of particules during the in-situ tests. Evolution of load vs diametral contraction is also highlighted for better understanding. c) corresponds to the evolution of the fraction of porosity ratio $f / f_{0}$.

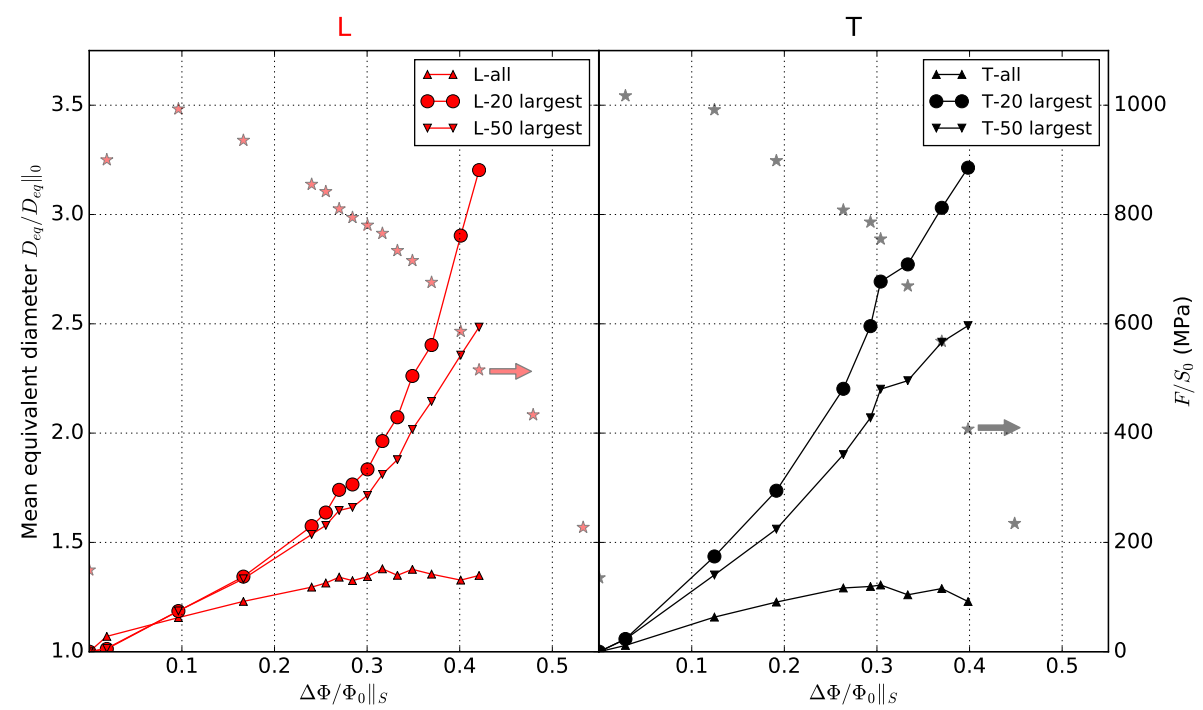

Figure 19: Evolution of the equivalent spherical diameter $D_{e q}=\sqrt[1 / 3]{\frac{6 V}{\pi}}$ during the in-situ tests for all and the 20 largest voids. Evolution of load vs diametral contraction is also highlighted for better understanding. 


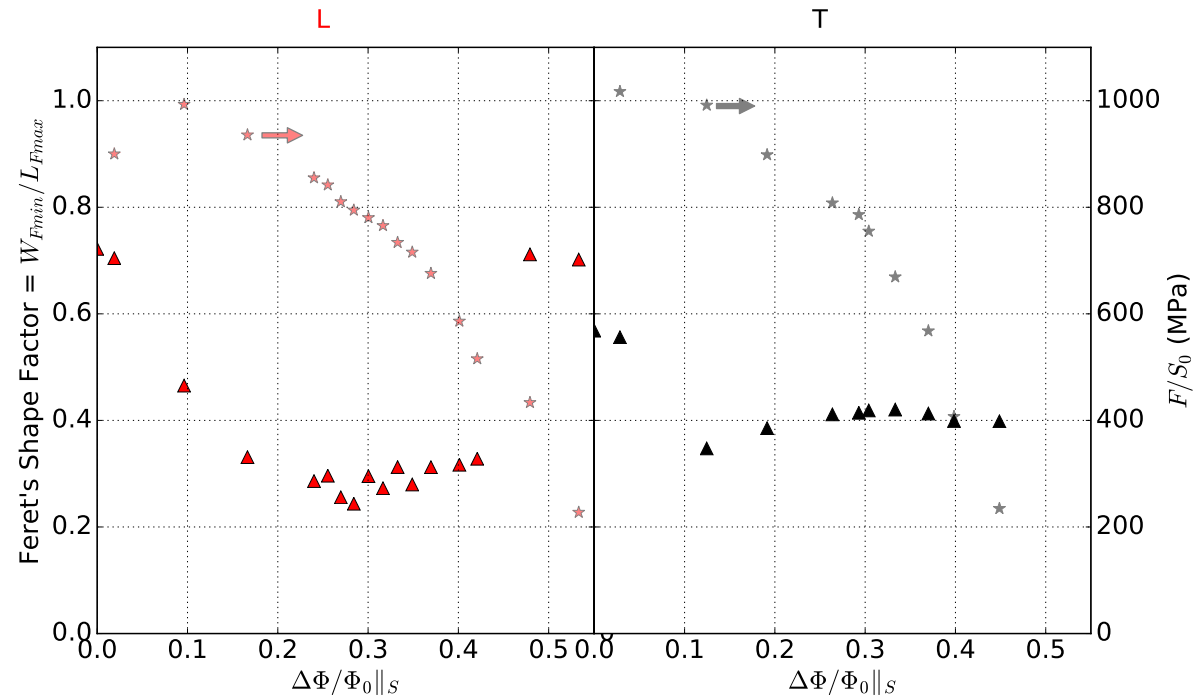

Figure 20: Evolution of Feret's Shape Factor $=W_{F \min } / L_{F \max }$ during the in-situ tests for the 20 largest voids. Evolution of load vs diametral contraction is also highlighted for better understanding.

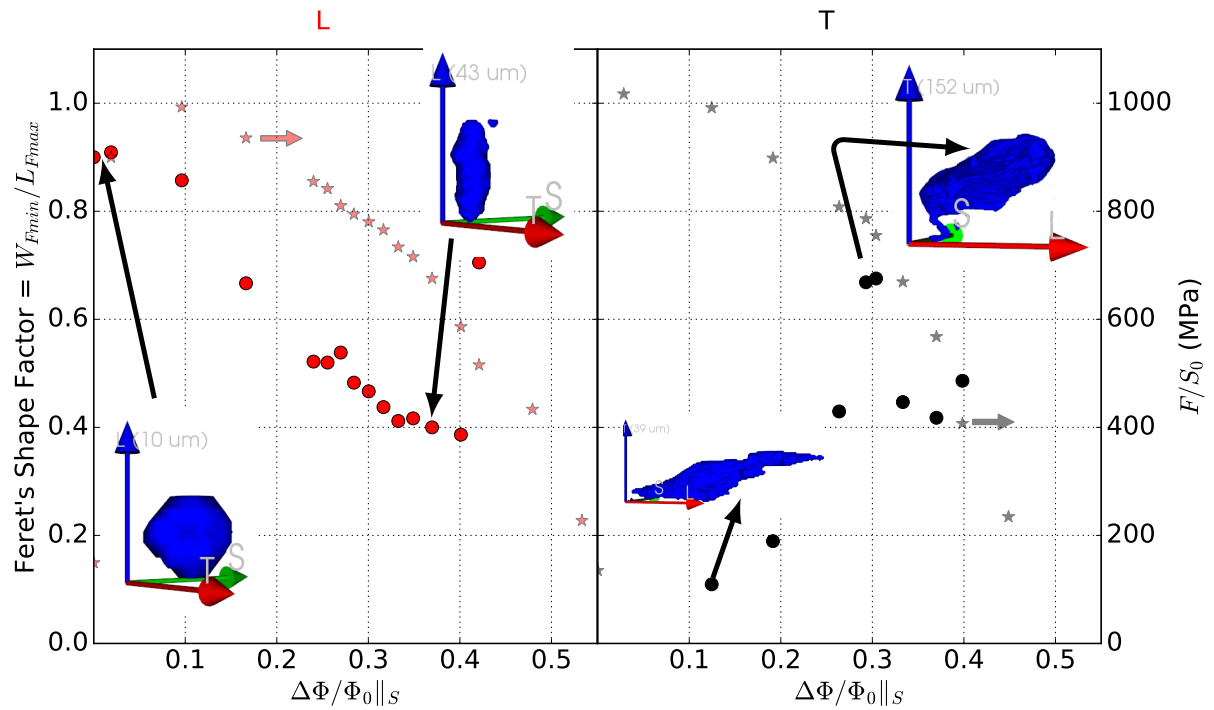

Figure 21: Evolution of Feret's Shape Factor $=W_{F \min } / L_{F \max }$ during the $i n$-situ tests for 1 particule within the clustering region. 


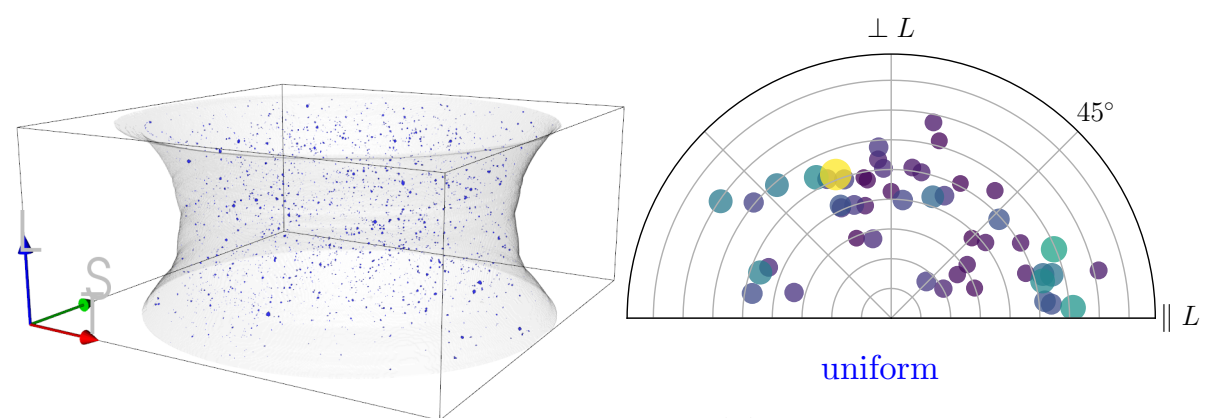

(b) $\gamma$ orientation of voids

(a) $3 \mathrm{D}$ visualization

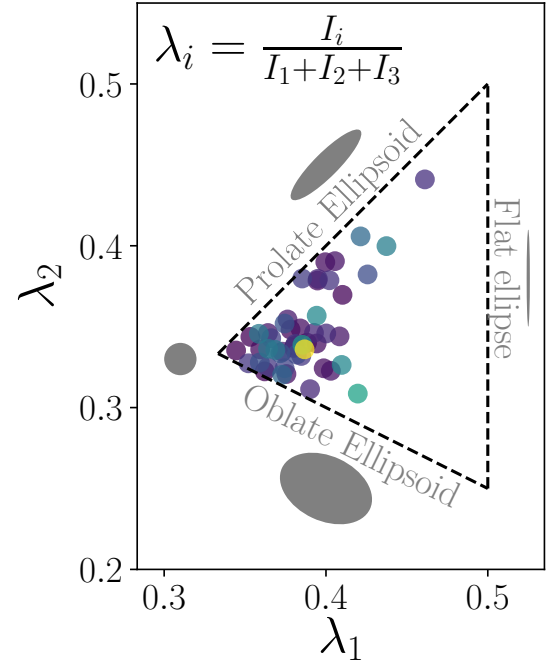

(c) Principal moments of inertia

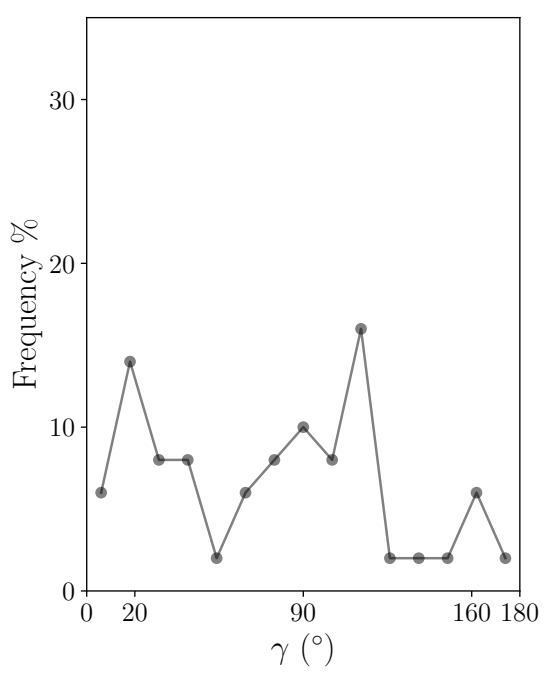

(d) Distribution of $\gamma$

Figure 22: L-specimen (step 1): (a) 3D vizualization and $\gamma$ angle orientation (with respect to the principal axis of the equivalent ellipsoid and the material $\mathrm{L}$ direction, $\gamma=0$ therefore corresponds to a cavity oriented along the L direction) and (b) shape characterization (Adimensional principal moments of inertia $\lambda_{2}$ vs $\lambda_{1}$ ) evolution during the in-situ test for the 50 largest individual particules. (c) Polar and (d) histogram plots are used to represent each $\gamma$ angle distribution wherein (for polar plot) radial component represents the distance from the center of the minimal cross-section of the sample (the marker size is related to the volume size of the cavity). 


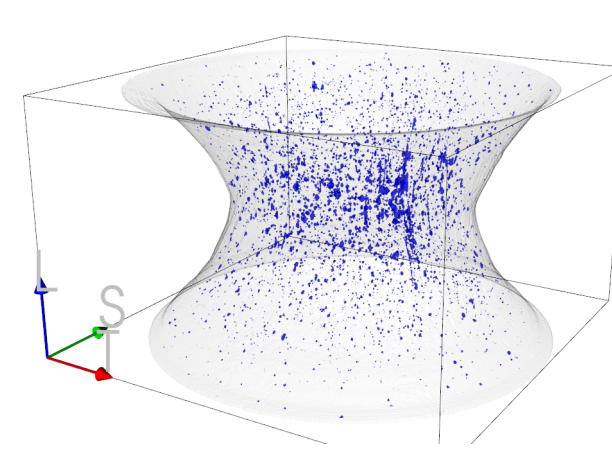

(a) $3 \mathrm{D}$ visualization

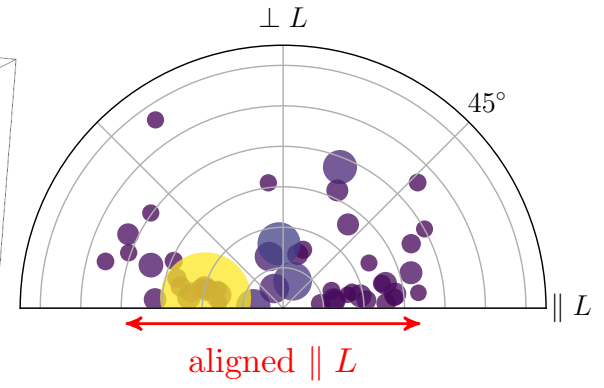

(b) $\gamma$ orientation of voids

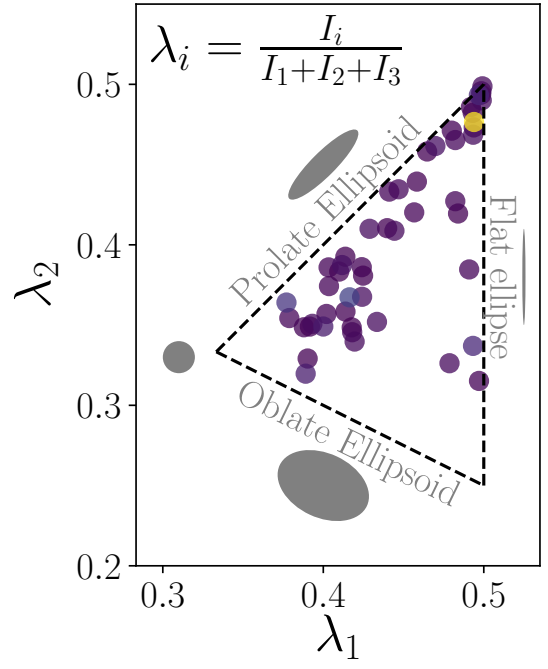

(c) Principal moments of inertia

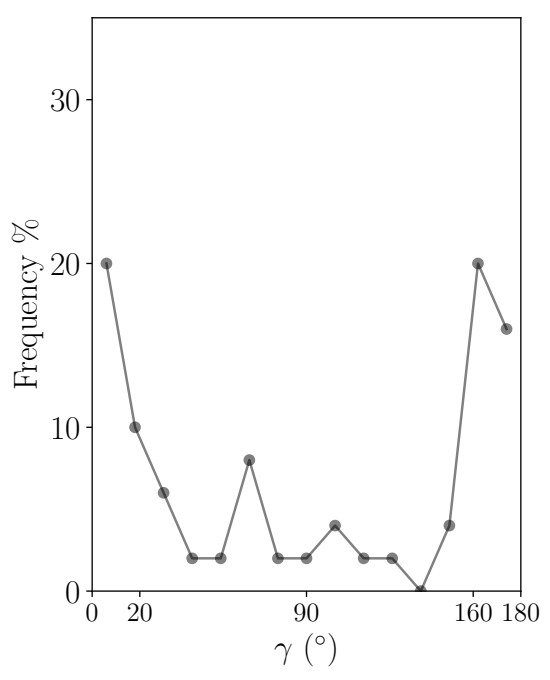

(d) Distribution of $\gamma$

Figure 23: L-specimen (step 10): (a) 3D vizualization and $\gamma$ angle orientation (with respect to the principal axis of the equivalent ellipsoid and the material $\mathrm{L}$ direction, $\gamma=0$ therefore corresponds to a cavity oriented along the $\mathrm{L}$ direction) and (b) shape characterization (Adimensional principal moments of inertia $\lambda_{2}$ vs $\lambda_{1}$ ) evolution during the in-situ test for the 50 largest individual particules. (c) Polar and (d) histogram plots are used to represent each $\gamma$ angle distribution wherein (for polar plot) radial component represents the distance from the center of the minimal cross-section of the sample (the marker size is related to the volume size of the cavity). 


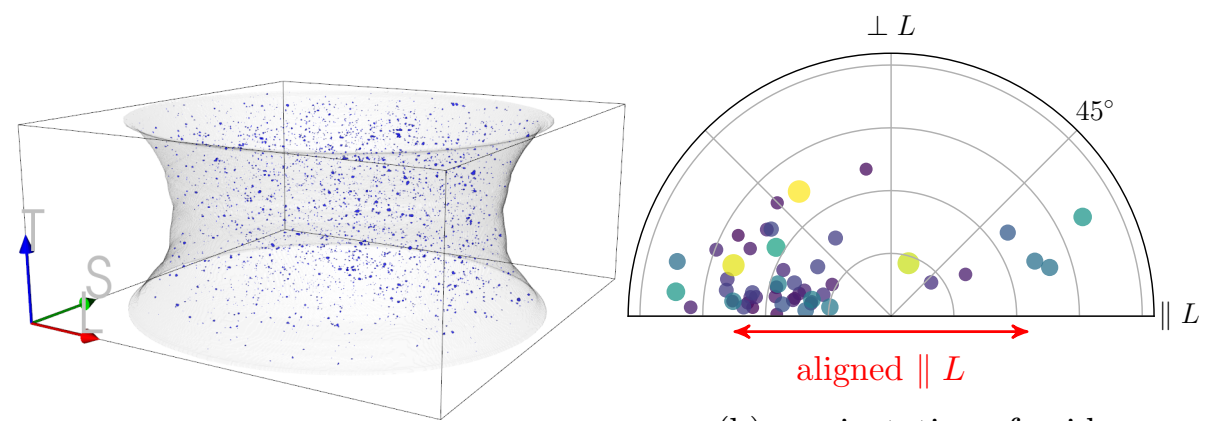

(b) $\gamma$ orientation of voids

(a) 3D visualization

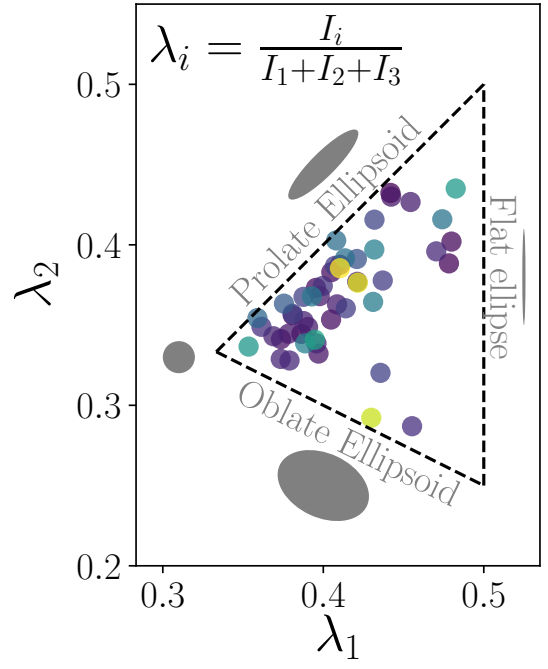

(c) Principal moments of inertia

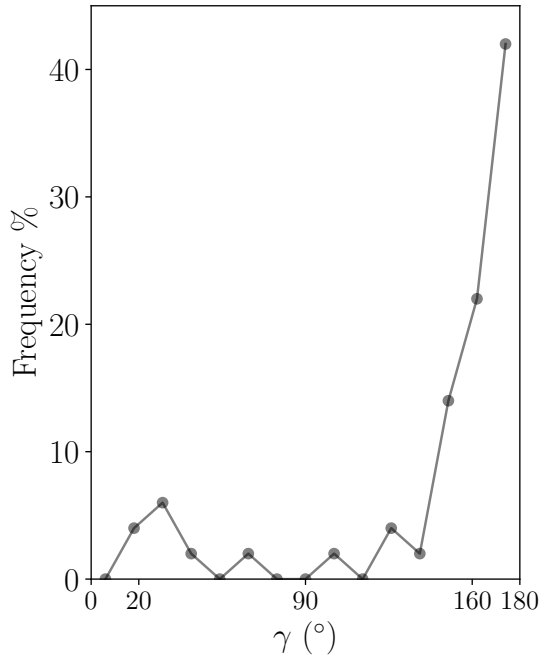

(d) Distribution of $\gamma$

Figure 24: T-specimen (step 01): (a) 3D vizualization and $\gamma$ angle orientation (with respect to the principal axis of the equivalent ellipsoid and the material $\mathrm{L}$ direction, $\gamma=0$ therefore corresponds to a cavity oriented along the $\mathrm{L}$ direction) and (b) shape characterization (Adimensional principal moments of inertia $\lambda_{2}$ vs $\lambda_{1}$ ) evolution during the in-situ test for the 50 largest individual particules. (c) Polar and (d) histogram plots are used to represent each $\gamma$ angle distribution wherein (for polar plot) radial component represents the distance from the center of the minimal cross-section of the sample (the marker size is related to the volume size of the cavity). 


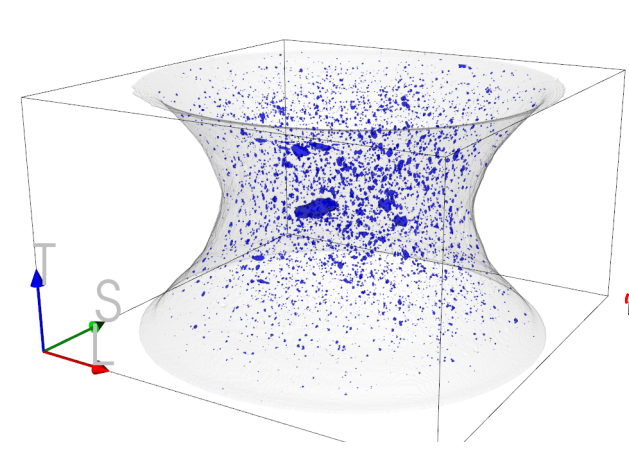

(a) $3 \mathrm{D}$ visualization

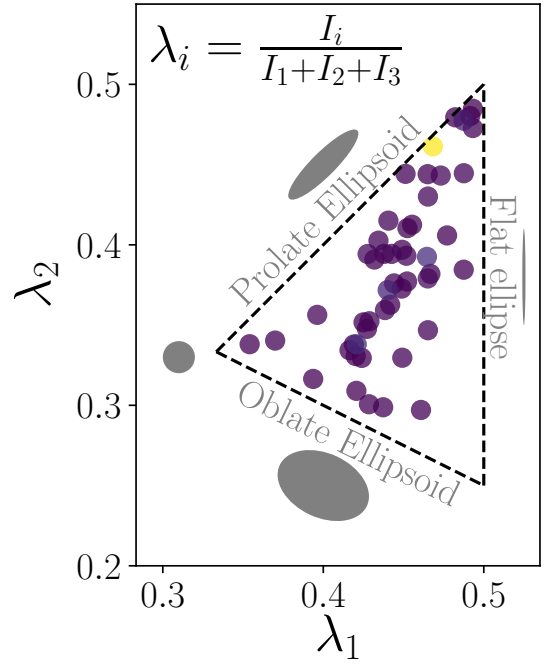

(c) Principal moments of inertia

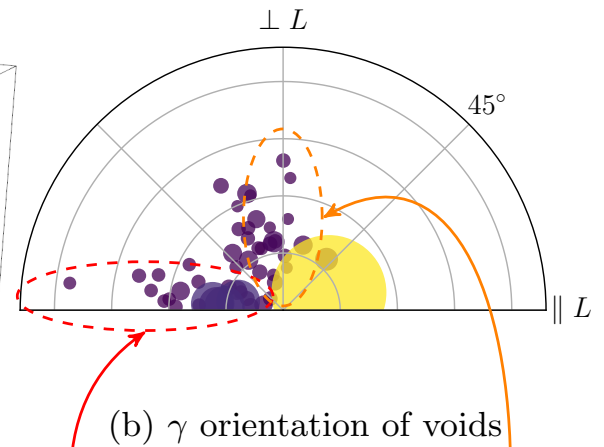

(b) $\gamma$ orientation of voids

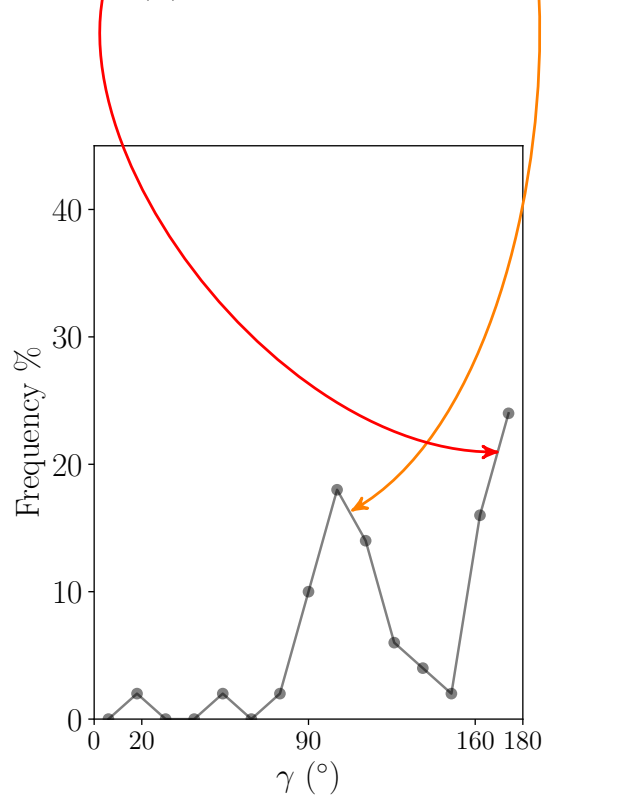

(d) Distribution of $\gamma$

Figure 25: T-specimen (step 05): (a) 3D vizualization and $\gamma$ angle orientation (with respect to the principal axis of the equivalent ellipsoid and the material $\mathrm{L}$ direction, $\gamma=0$ therefore corresponds to a cavity oriented along the L direction) and (b) shape characterization (Adimensional principal moments of inertia $\lambda_{2}$ vs $\lambda_{1}$ ) evolution during the in-situ test for the 50 largest individual particules. (c) Polar and (d) histogram plots are used to represent each $\gamma$ angle distribution wherein (for polar plot) radial component represents the distance from the center of the minimal cross-section of the sample (the marker size is related to the volume size of the cavity). 
Appendix A. 2D sections for the measurement of the ellipse of the minimal cross-section 

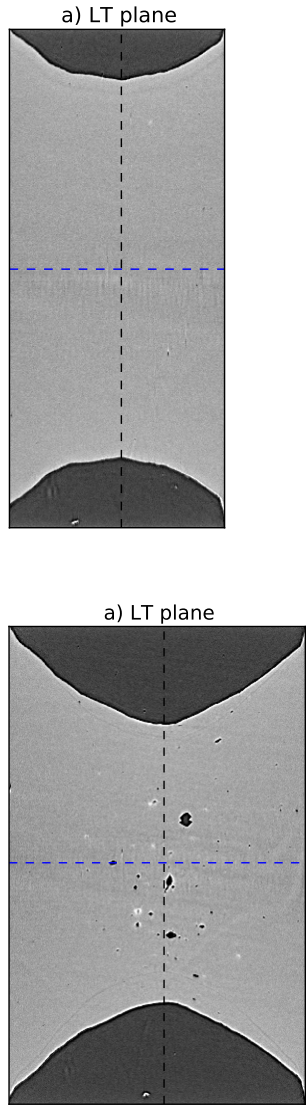

a) LT plane

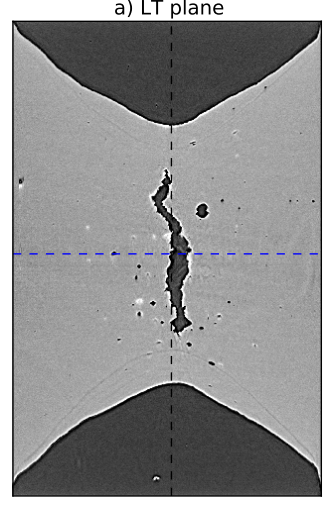

b) LS plane

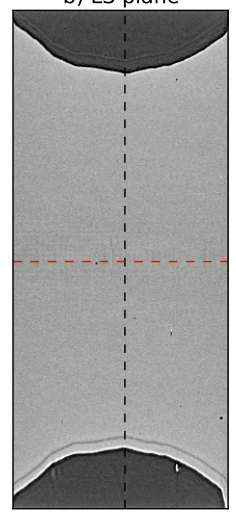

(a) Step 1

b) LS plane

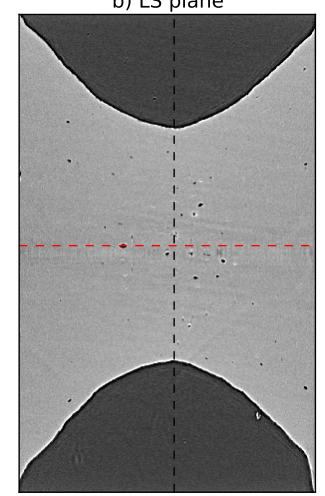

(b) Step 12

b) LS plane
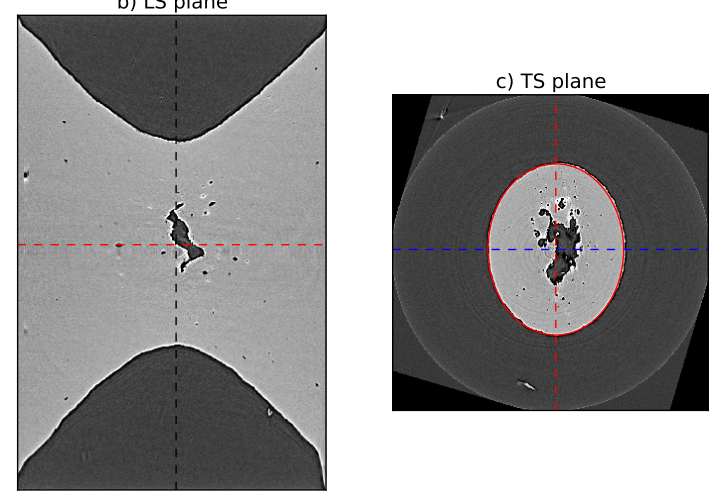

(c) Step 15

Figure A.26: Extraction of 2D sections from the 3D volume for a few L-loading steps. The minimum cross-section is represented by an ellipse whose main axes are oriented in directions $\mathrm{T}$ and $\mathrm{S}$ for specimen $\mathrm{L}$, in directions $\mathrm{L}$ and $\mathrm{S}$ for specimen $\mathrm{T}$. The diameter reduction in these directions is deduced from the measurement of the main axes of the ellipse. 
a) TL plane

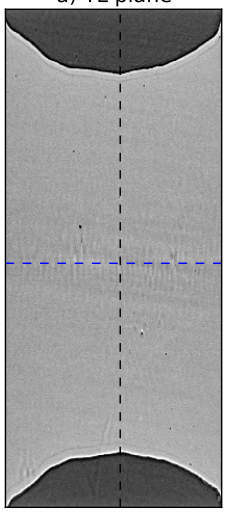

a) TL plane

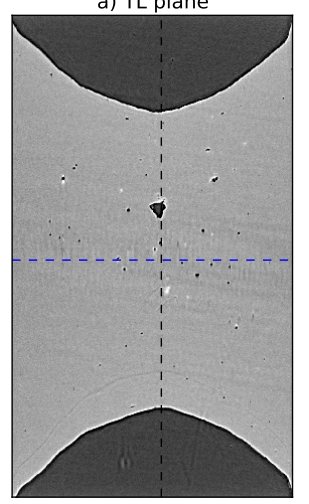

a) TL plane

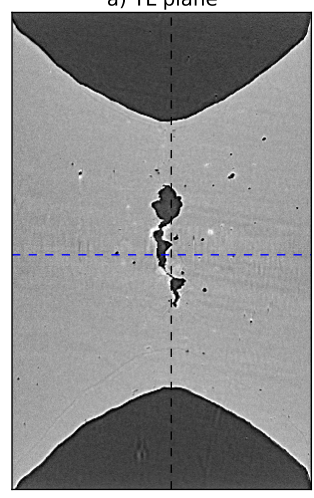

b) TS plane

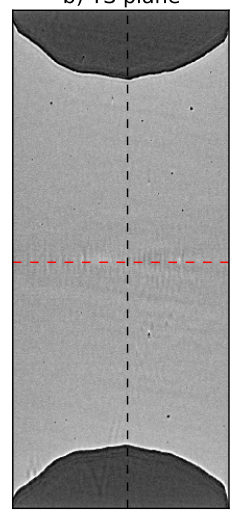

(a) Step 1

b) TS plane

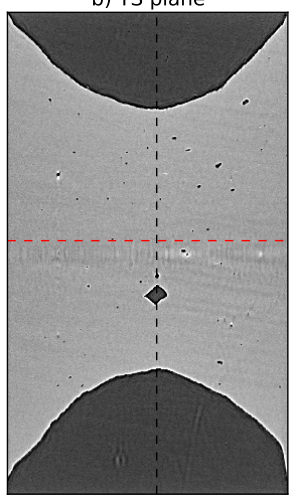

(b) Step 5

b) TS plane
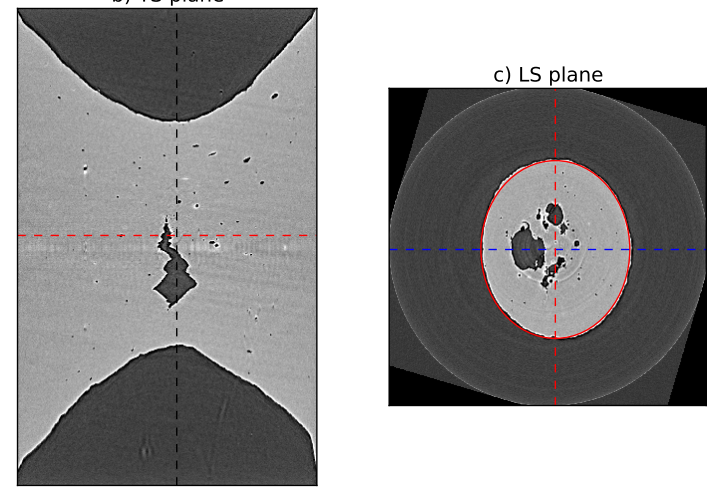

(c) Step 09

Figure A.27: Extraction of 2D sections from the 3D volume for a few T-loading steps. The minimum cross-section is represented by an ellipse whose main axes are oriented in directions $\mathrm{T}$ and $\mathrm{S}$ for specimen $\mathrm{L}$, in directions $\mathrm{L}$ and $\mathrm{S}$ for specimen $\mathrm{T}$. The diameter reduction in these directions is deduced from the measurement of the main axes of the ellipse. 
Appendix B. Statistical analysis of all porosities

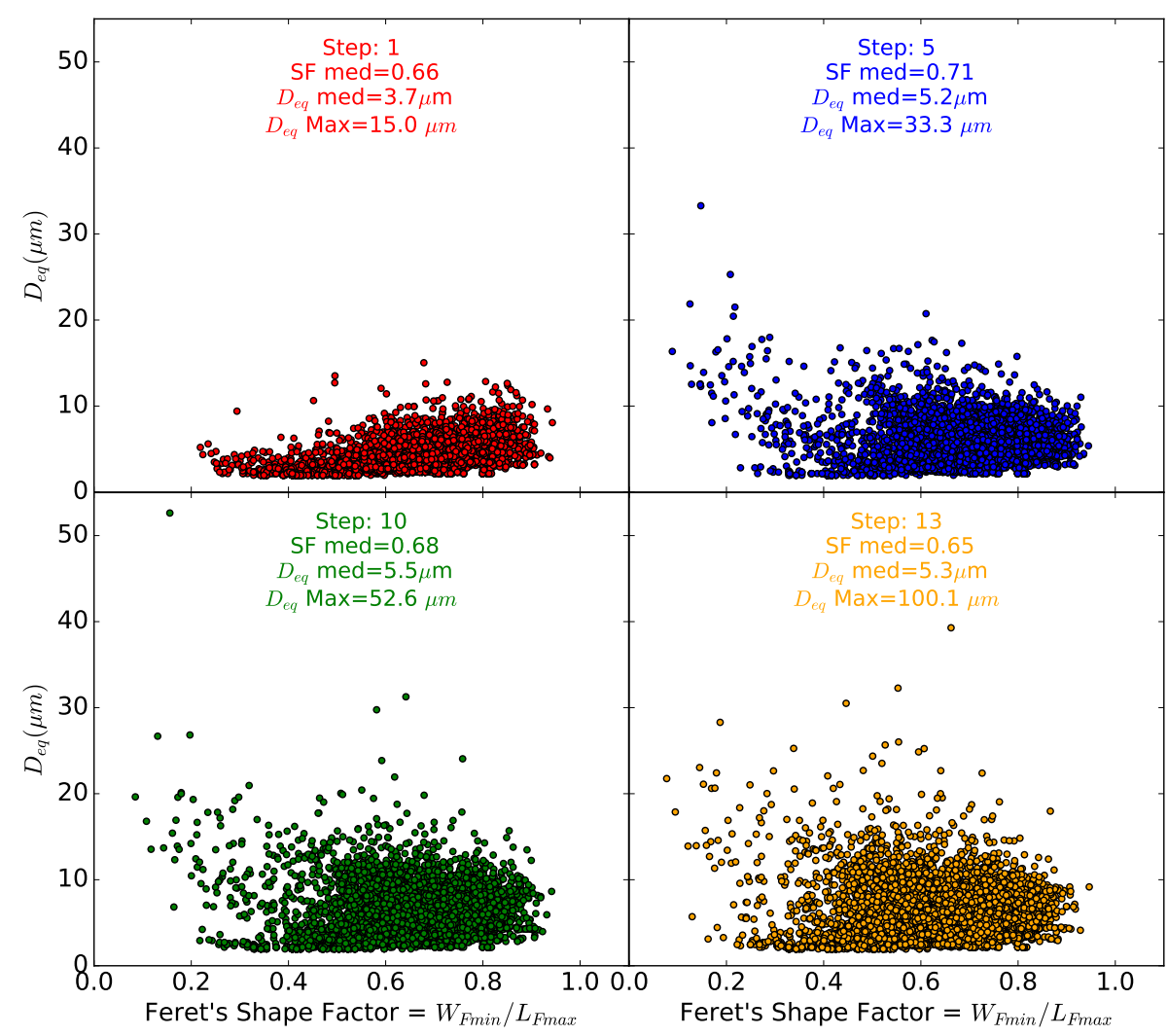

Figure B.28: Evolution of Feret's shape factor with respect to the volume size for L loading direction, All porosities, steps number: 1, 5, 10, 13. 


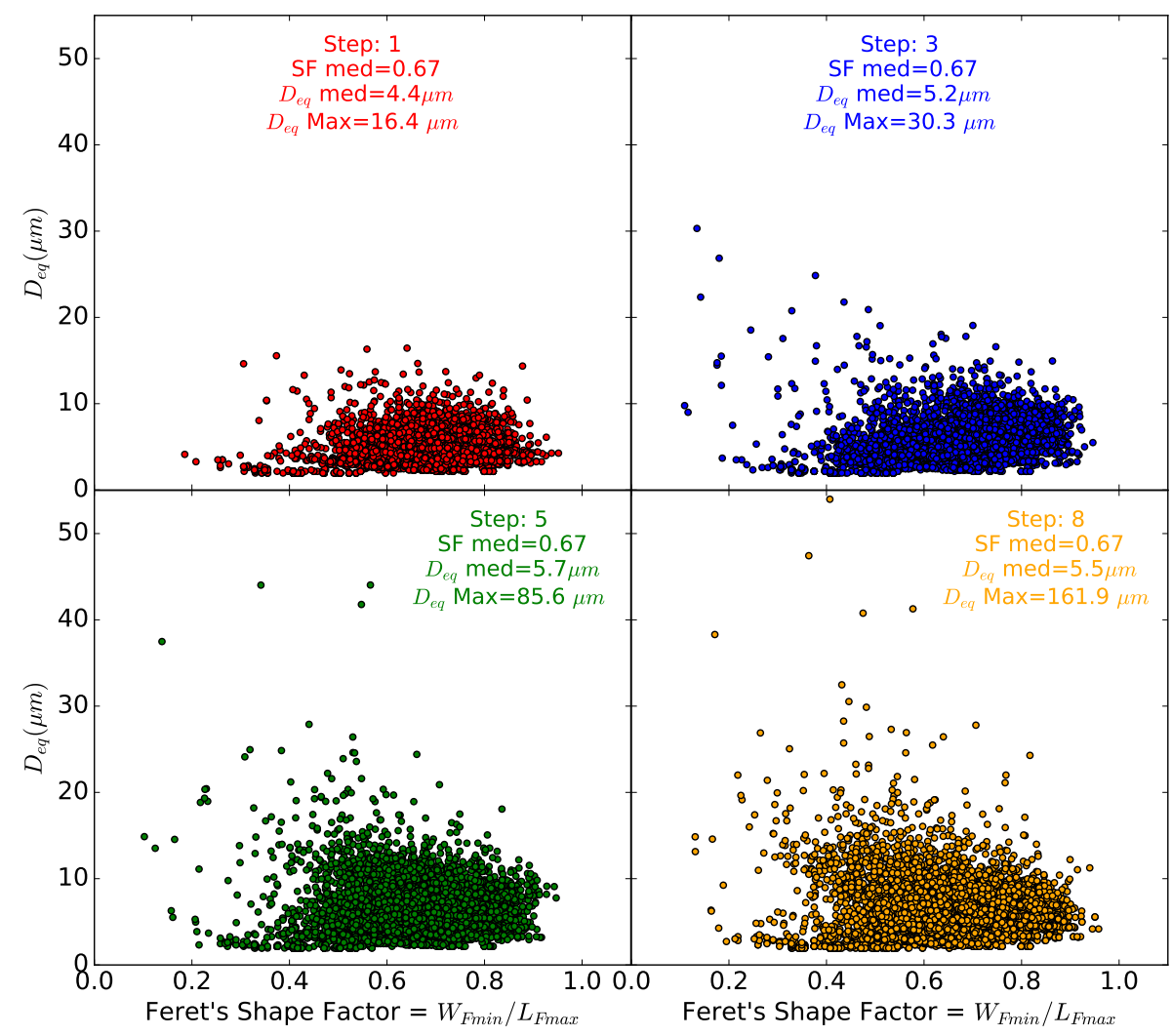

Figure B.29: Evolution of Feret's shape factor with respect to the volume size for L loading direction, All porosities, steps number: 1, 3, 5, 8 . 


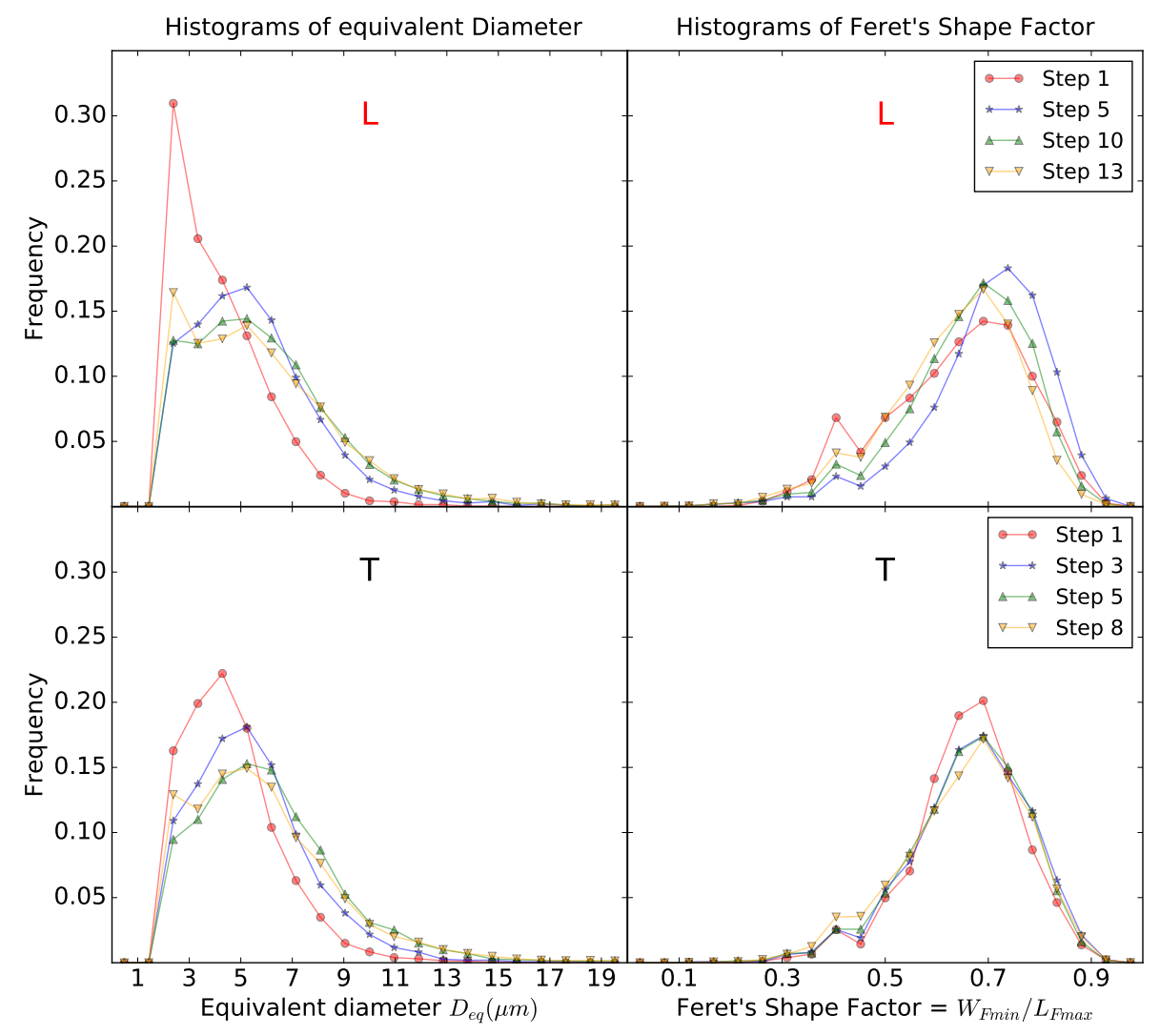

Figure B.30: Histograms of the equivalent spherical diameter $D_{e q}=\sqrt[3]{\frac{6 V}{\pi}}$ and the Feret's shape factor, All porosities: for L loading direction, steps number: $1,5,10,13$ and for $\mathrm{T}$ loading direction, steps number: $1,3,5,8$. 
Appendix C. Void shape and void orientation analysis: complementary results 


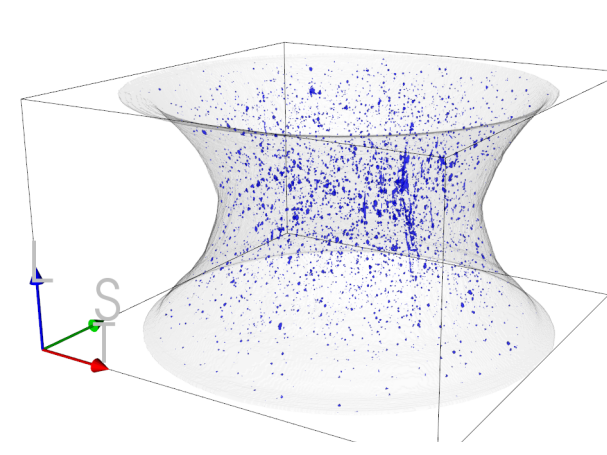

(a) $3 \mathrm{D}$ visualization

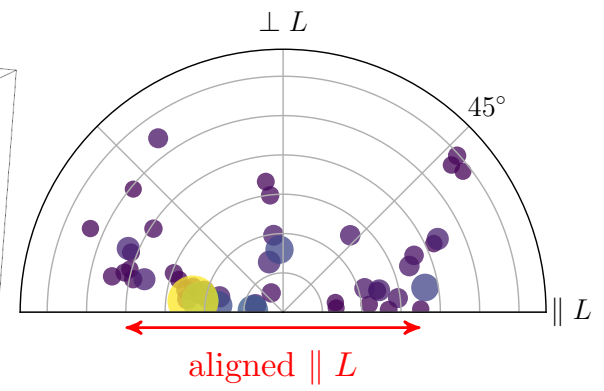

(b) $\gamma$ orientation of voids

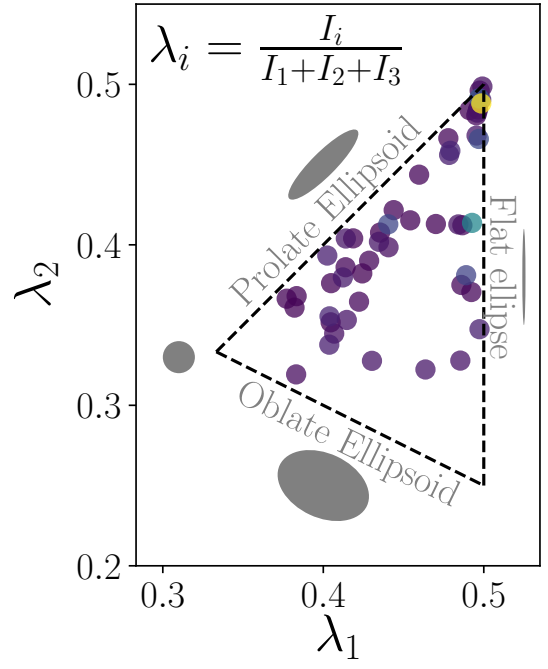

(c) Principal moments of inertia

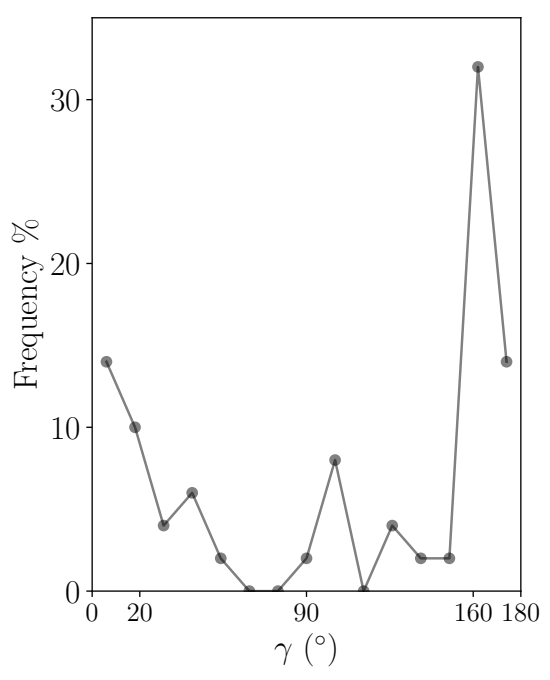

(d) Distribution of $\gamma$

Figure C.31: L-specimen (step 05): (a) 3D vizualization and $\gamma$ angle orientation (with respect to the principal axis of the equivalent ellipsoid and the material $\mathrm{L}$ direction, $\gamma=0$ therefore corresponds to a cavity oriented along the $\mathrm{L}$ direction) and (b) shape characterization (Adimensional principal moments of inertia $\lambda_{2}$ vs $\lambda_{1}$ ) evolution during the in-situ test for the 50 largest individual particules. (c) Polar and (d) histogram plots are used to represent each $\gamma$ angle distribution wherein (for polar plot) radial component represents the distance from the center of the minimal cross-section of the sample (the marker size is related to the volume size of the cavity). 


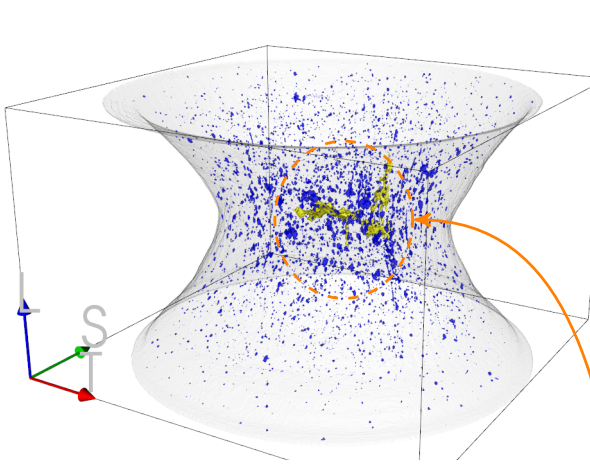

(a) $3 \mathrm{D}$ visualization

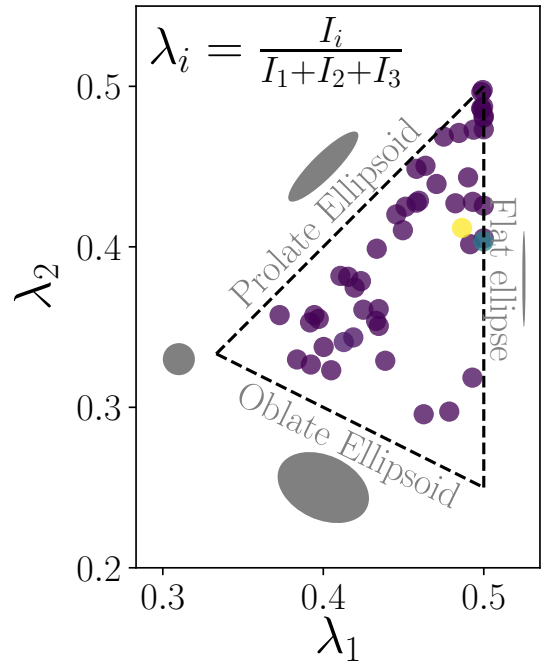

(c) Principal moments of inertia

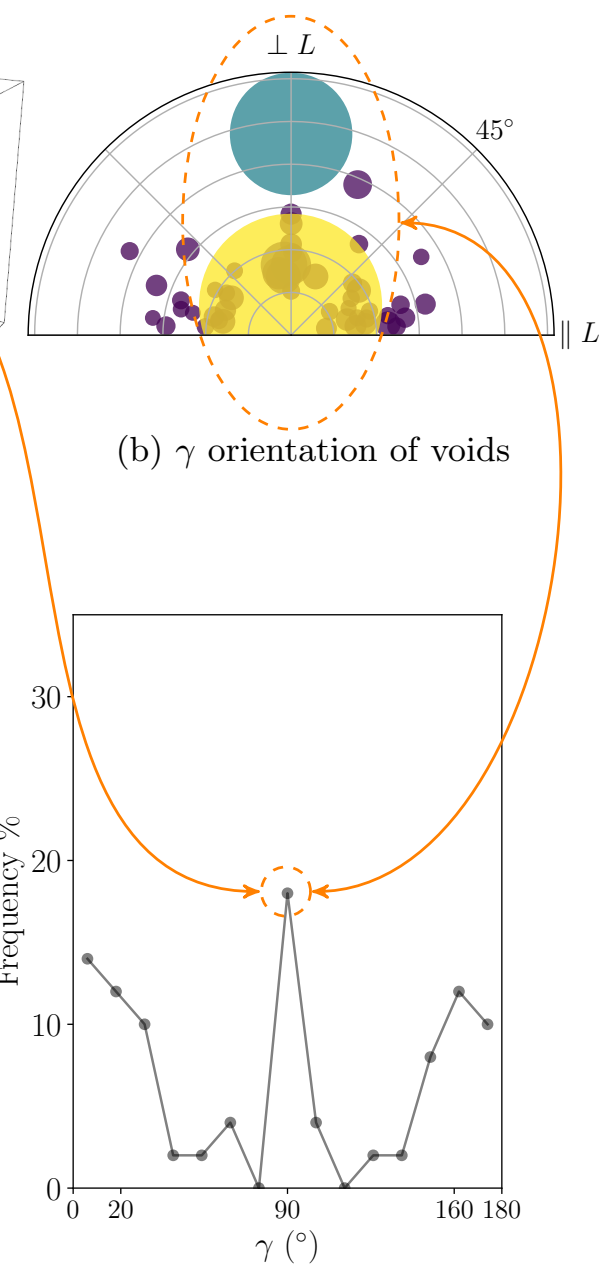

(d) Distribution of $\gamma$

Figure C.32: L-specimen (step 13): (a) 3D vizualization and $\gamma$ angle orientation (with respect to the principal axis of the equivalent ellipsoid and the material $\mathrm{L}$ direction, $\gamma=0$ therefore corresponds to a cavity oriented along the L direction) and (b) shape characterization (Adimensional principal moments of inertia $\lambda_{2}$ vs $\lambda_{1}$ ) evolution during the in-situ test for the 50 largest individual particules. (c) Polar and (d) histogram plots are used to represent each $\gamma$ angle distribution wherein (for polar plot) radial component represents the distance from the center of the minimal cross-section of the sample (the marker size is related to the volume size of the cavity). 


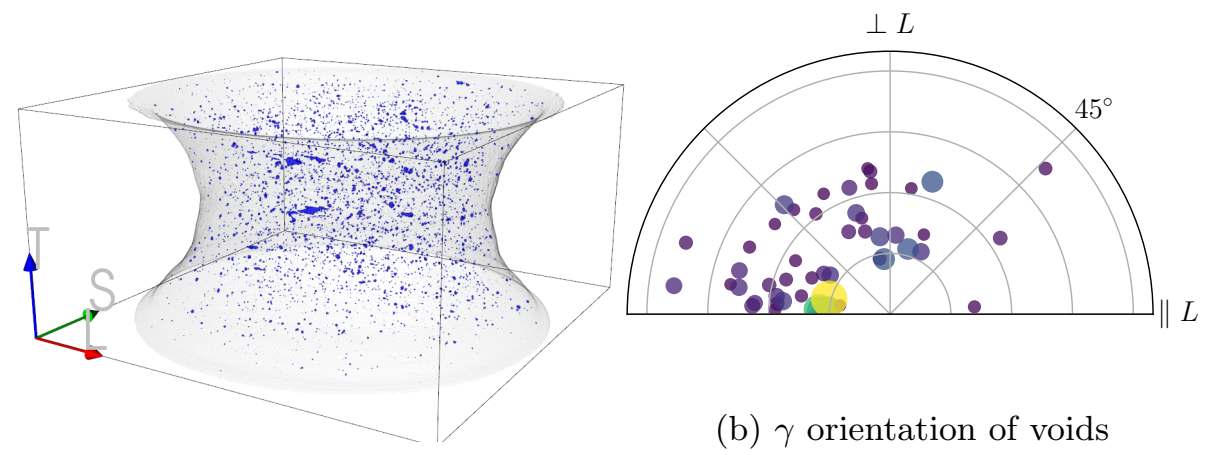

(a) 3D visualization

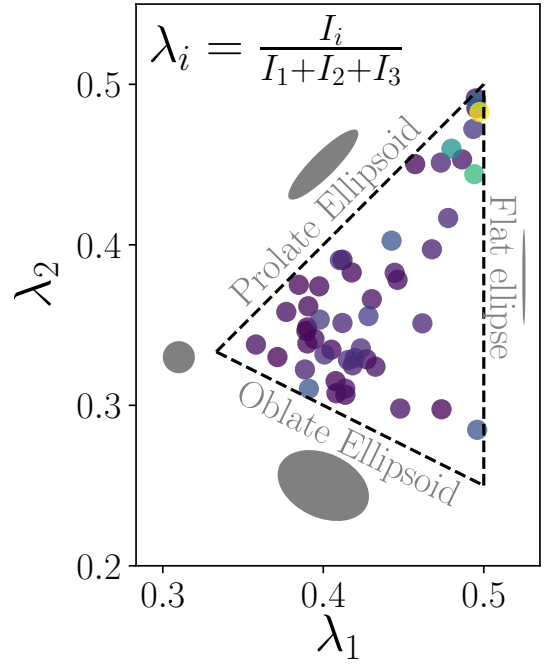

(c) Principal moments of inertia

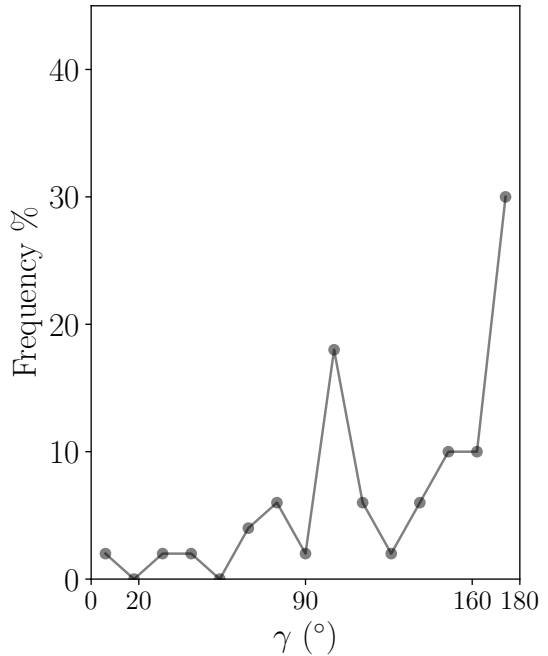

(d) Distribution of $\gamma$

Figure C.33: L-specimen (step 03): (a) 3D vizualization and $\gamma$ angle orientation (with respect to the principal axis of the equivalent ellipsoid and the material $\mathrm{L}$ direction, $\gamma=0$ therefore corresponds to a cavity oriented along the L direction) and (b) shape characterization (Adimensional principal moments of inertia $\lambda_{2}$ vs $\lambda_{1}$ ) evolution during the in-situ test for the 50 largest individual particules. (c) Polar and (d) histogram plots are used to represent each $\gamma$ angle distribution wherein (for polar plot) radial component represents the distance from the center of the minimal cross-section of the sample (the marker size is related to the volume size of the cavity). 


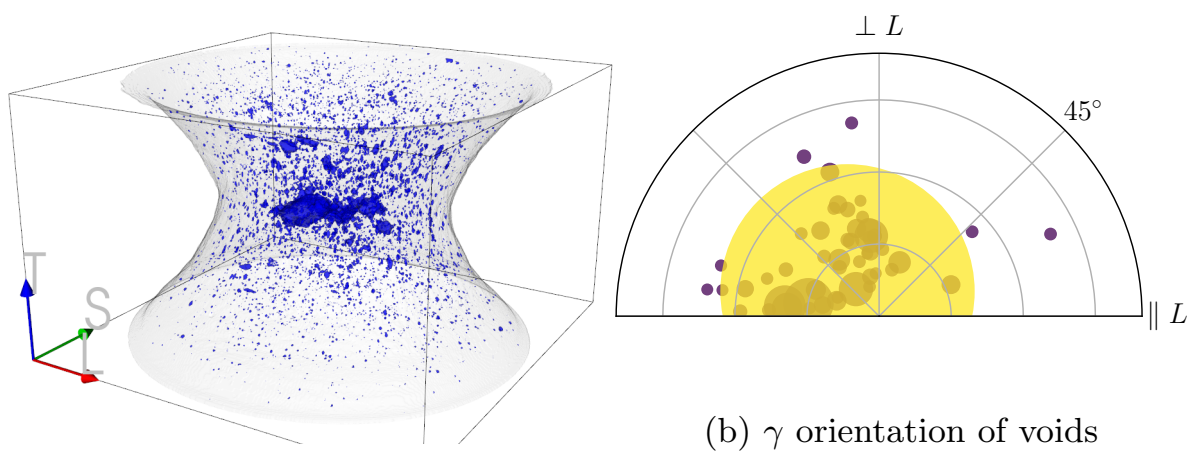

(a) 3D visualization

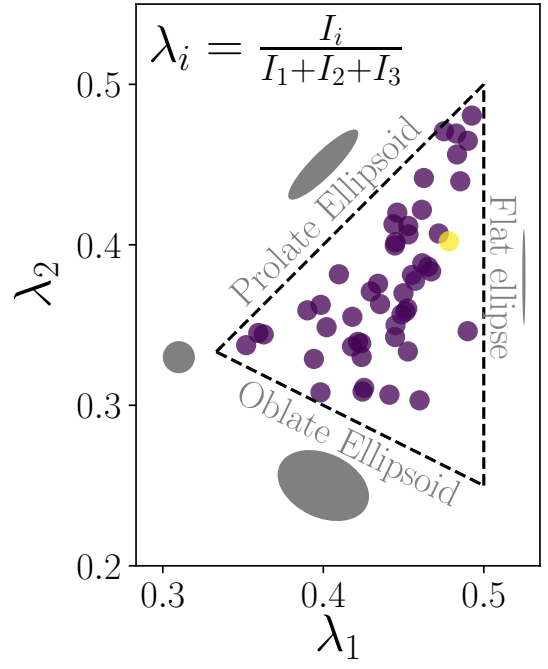

(c) Principal moments of inertia

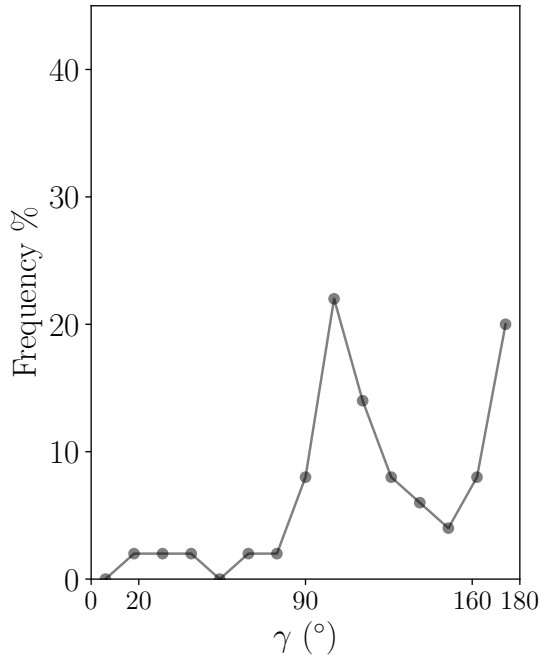

(d) Distribution of $\gamma$

Figure C.34: L-specimen (step 08): (a) 3D vizualization and $\gamma$ angle orientation (with respect to the principal axis of the equivalent ellipsoid and the material $\mathrm{L}$ direction, $\gamma=0$ therefore corresponds to a cavity oriented along the L direction) and (b) shape characterization (Adimensional principal moments of inertia $\lambda_{2}$ vs $\lambda_{1}$ ) evolution during the in-situ test for the 50 largest individual particules. (c) Polar and (d) histogram plots are used to represent each $\gamma$ angle distribution wherein (for polar plot) radial component represents the distance from the center of the minimal cross-section of the sample (the marker size is related to the volume size of the cavity). 